\title{
¿Land Surface Temperature from GOES-East and GOES-West
}

\author{
Wen Chen, ${ }^{a}$ Rachel T. Pinker, ${ }^{\mathrm{a}}$ Yingtao Ma, ${ }^{\mathrm{a}}$ Glynn Hulley, ${ }^{\mathrm{b}}$ Eva Borbas, ${ }^{\mathrm{c}}$ TAnvir Islam, ${ }^{\mathrm{b}}$ \\ Kerry-A. CAwse-Nicholson, ${ }^{\mathrm{b}}$ SimOn HoOK, ${ }^{\mathrm{b}}$ CHris Hain, ${ }^{\mathrm{d}}$ AND JeFF Basara ${ }^{\mathrm{e}}$ \\ a Department of Atmospheric and Oceanic Science, University of Maryland, College Park, College Park, Maryland \\ ${ }^{\mathrm{b}}$ Jet Propulsion Laboratory, California Institute of Technology, Pasadena, California \\ ${ }^{\mathrm{c}}$ Cooperative Institute for Meteorological Satellite Studies, Space Science and Engineering Center, \\ University of Wisconsin-Madison, Madison, Wisconsin \\ ${ }^{\mathrm{d}}$ NASA Marshall Space Flight Center, Huntsville, Alabama \\ ${ }^{\text {e }}$ School of Meteorology, University of Oklahoma, Norman, Oklahoma
}

(Manuscript received 10 June 2020, in final form 23 December 2020)

\begin{abstract}
Land surface temperature (LST) is an important climate parameter that controls the surface energy budget. For climate applications, information is needed at the global scale with representation of the diurnal cycle. To achieve global coverage there is a need to merge about five independent geostationary (GEO) satellites that have different observing capabilities. An issue of practical importance is the merging of independent satellite observations in areas of overlap. An optimal approach in such areas could eliminate the need for redundant computations by differently viewing satellites. We use a previously developed approach to derive information on LST from GOES-East (GOES-E), modify it for application to GOES-West (GOES-W) and implement it simultaneously across areas of overlap at 5-km spatial resolution. We evaluate the GOES-based LST against in situ observations and an independent MODIS product for the period of 2004-09. The methodology proposed minimizes differences between satellites in areas of overlap. The mean and median values of the differences in monthly mean LST retrieved from GOES-E and GOES-W at 0600 UTC for July are 0.01 and $0.11 \mathrm{~K}$, respectively. Similarly, at $1800 \mathrm{UTC}$ the respective mean and median value of the differences were 0.15 and $1.33 \mathrm{~K}$. These findings can provide guidelines for potential users to decide whether the reported accuracy based on one satellite alone, meets their needs in area of overlap. Since the $6 \mathrm{yr}$ record of LST was produced at hourly time scale, the data are well suited to address scientific issues that require the representation of LST diurnal cycle or the diurnal temperature range (DTR).
\end{abstract}

KEYWORDS: Surface temperature; Algorithms; Remote sensing; Satellite observations

\section{Introduction}

Many attempts have been made to estimate land surface temperature (LST) from satellite observations at various temporal and spatial scales (e.g., Becker and Li 1990, 1995; McFarland et al. 1990; Sobrino et al. 1994; Wan and Li 1997; Schmugge et al. 1998; Snyder et al. 1998; Sun and Pinker 2003, 2005; Pinker et al. 2009; Yu et al. 2005, 2009; Duan et al. 2014; Ren et al. 2018; Zheng et al. 2019). The objective of these studies varied from validation of climate models to modeling evapotranspiration of land surface, energy and water balance and draft detection (e.g., Fuchs 1990; Anderson et al. 2007, 2011; Kustas and Anderson 2009; Li et al. 2009; Karnieli et al. 2010; Tomlinson et al. 2011; Wang et al. 2014). Only in few previous studies attention has been paid to the diurnal cycle. In one such early attempt, Ignatov and Gutman (1999) used the 3 hourly International Satellite Cloud Climatology Project (ISCCP) data (at $280 \mathrm{~km}$ resolution) (Rossow and Schiffer 1991) in combination with ground observations, to derive the monthly mean diurnal cycle in surface temperature over land,

\footnotetext{
D Denotes content that is immediately available upon publication as open access.
}

Corresponding author: Rachel T. Pinker, pinker@atmos. umd.edu suitable for global climate studies. Duan et al. (2014) tried the same using high-spatial-resolution data from clear-sky MODIS observations while Inamdar et al. (2008) disaggregated the diurnal cycle of LST at the Geostationary Operational Environment Satellite (GOES) pixel scale to that at the MODIS pixel scale. Wang and Prigent (2020) compared the diurnal variations of LSTs for a full season in 2010 using reanalysis results from the European Centre for Medium-Range Weather Forecasts (ECMWF) reanalysis (ERA-Interim and ERA5), infrared satellite observations from an updated ISCCP product (Young et al. 2018), the Spinning Enhanced Visible and Infrared Imager (SEVIRI), and in situ measurements. They found that SEVIRI had closer agreement with the in situ measurements than the other products with a bias often less than $\pm 2 \mathrm{~K}$. Over snow or in arid areas ISCCP had more systematic errors than the other products; both reanalyses had higher (lower) estimations at nighttime (daytime) than the in situ measurements. To explore such variability, there is a need to establish a consistent and seamless long-term global record of land surface properties, which requires to homogenize satellite observations from several sources (e.g., Pinheiro et al. 2006; Susskind and Blaisdell 2008; Seemann et al. 2008; Anderson et al. 2011; Hulley and Hook 2011; Hulley et al. 2018; Ermida et al. 2017, 2018, 2020). For instance, Scarino et al. (2013, 2017) used a single-channel thermal-infrared (TIR) method to retrieve surface LST under clear-sky from geostationary-Earth-orbit (GEO) and low-Earth-orbit (LEO) 
TABLE 1. Selected GOES Imager scan sectors in routine mode.

\begin{tabular}{|c|c|c|c|c|}
\hline Satellite system & Frame name & Boundaries & Duration (mm:ss) & Scan times $^{\mathrm{a}}$ (UTC) \\
\hline GOES-E & Extended Northern Hemisphere & $20^{\circ} \mathrm{S}-66^{\circ} \mathrm{N}, 45^{\circ}-120^{\circ} \mathrm{W}$ & $14: 16$ & hh15, hh45 \\
\hline GOES-W & Northern Hemisphere & $0^{\circ}-66^{\circ} \mathrm{N}, 90^{\circ} \mathrm{W}-170^{\circ} \mathrm{E}$ & 9:00 & hh00, hh30 \\
\hline
\end{tabular}

${ }^{\mathrm{a}}$ The GOES-E observations and the GOES-W observations have $15 \mathrm{~min}$ time difference.

satellite imagers. They used an empirically adjusted theoretical model of angular anisotropy (Vinnikov et al. 2012) to improve the satellite LST retrievals. They demonstrated that the application of the anisotropic correction yields reduced mean bias and improved precision for GOES-13 LST relative to independent Moderate Resolution Imaging Spectroradiometer (MYD11_L2) retrievals and also against the Atmospheric Radiation Measurement (ARM) program ground observations (Ackerman et al. 2016). Geostationary satellite data at high temporal and spatial resolution could provide a detailed depiction of the LST diurnal cycle.

In the present study we use satellite observations of the highest practical spatial (5-km) and temporal (hourly) resolutions and formulate a framework for deriving LST from both GOES-East (GOES-E) and GOES-West (GOES-W) utilizing a recently developed inference scheme (Pinker et al. 2019) that inherently accounts for atmospheric anisotropy and utilizes recent auxiliary information from the ModernEra Retrospective Analysis for Research and Applications (MERRA-2) (Gelaro et al. 2017). We report on results obtained during the period (2004-09) over the United States and we investigate the potential of the satellite products to reproduce the diurnal cycle and diurnal temperature range (DTR) as observed by ground observations. The methodology is described in section 2; results are discussed in section 3; summary and discussion are provided in section 4.

\section{Approach}

\section{a. Review of retrieval methodology}

The GOES systems (East and West) provide readily available data at high temporal frequency (every half hour) at continental-scale coverage (https://www.bou.class.noaa.gov/ release/index.htm). The imager scan sectors in routine mode is shown in Table 1. The present study is based on observations at 15 and $30 \mathrm{~min}$ after each hour from GOES-12 (GOES-E) and GOES-10/GOES-11 (GOES-W), respectively.

Typically, the GOES imager includes five spectral channels (one visible, four infrared, Table 2). Before deriving the LST, all channels except 3 and 6 are calibrated (Gunshor et al. 2009; Weinreb et al. 2007) and used in a cloud screening algorithm (Pinker et al. 2019).

The LST retrieval algorithm is a single channel approach using channel $4(10.7 \mu \mathrm{m})$ observations as described in Pinker et al. (2019) and briefly repeated here for the convenience of the readers:

$$
T_{s}=B^{-1}\left\{\frac{1}{\epsilon}\left[\frac{1}{X}\left(R_{o}^{\uparrow}-R_{a}^{\uparrow}\right)-(1-\epsilon) R_{a}^{\downarrow}\right]\right\},
$$

"where $B^{-1}$ denote[s] the inverse of Planck function for GOES-12 channel 4," " $\varepsilon$ is surface emissivity," " $X$ denotes the atmospheric transmittance," $R_{o}^{\uparrow}$ is the satellite observed radiance, " $R_{a}^{\uparrow}$ and $R_{a}^{\downarrow}$ are atmospheric emission to space and surface, respectively. With known surface emissivity and simulated atmospheric emission and transmittance, the surface temperature can be derived." Specifically, the approach uses the Radiative Transfer for TOVS (RTTOV) model v11.2 (Saunders et al. 1999; Matricardi and Saunders 1999) adjusted for the GEO characteristics to simulate atmospheric emissions. The four-times-daily (0000, 0600, 1200, 1800 UTC) MERRA-2 date are used to specify the atmospheric state. Since the LST is retrieved hourly, the MERRA-2 data need to be linearly interpolated in time in between the four analyses times. The MODIS-ASTER global infrared combined emissivity information produced from the University of Wisconsin Global Infrared Land Surface Emissivity (UWIREMIS) and the ASTER Global Emissivity Database (GED) [Combined ASTER MODIS Emissivity over Land (CAMEL)] (Borbas et al. 2018; Feltz et al. 2018; Hulley and Hook 2011) is also implemented in the methodology for deriving LST. It has been successfully applied to GOES-12 (4 January 2003-14 April 2010) observations and a detailed description of the methodology including calibration of GOES raw imaging data, implementation of cloud screening algorithm and ancillary data can be found in Pinker et al. (2019). The added benefit of this retrieval approach is that it is consistent with the one used at the Jet Propulsion Laboratory (JPL) to generate the MOD21 product (Hulley et al. 2014) allowing future intercomparisons. In the following section we describe modifications needed before one can apply this approach to GOES-W.

\section{b. Issue of GOES-E and GOES-W overlap}

Figures $1 \mathrm{a}$ and $1 \mathrm{~b}$ show the GOES-W coverage used and a calibrated image. For GOES-W, the images are of different size and dimension than those for GOES-E. They need to be regenerated to allow the use of existing screening code and ancillary information in the formats used for GOES-E. This is

TABLE 2. Summary of GOES imager channels.

\begin{tabular}{lccc}
\hline Satellite & Channel & $\begin{array}{c}\text { Wavelength } \\
(\mu \mathrm{m})\end{array}$ & $\begin{array}{c}\text { Spatial resolution } \\
\text { (nadir; km) }\end{array}$ \\
\hline GOES-10/-11/-12 & 1 & 0.67 & 1 \\
& 2 & 3.9 & 4 \\
& 3 & 6.7 & 4 \\
GOES-10/-11 & 4 & 10.7 & 4 \\
GOES-12 & 5 & 12.0 & 4 \\
\hline
\end{tabular}



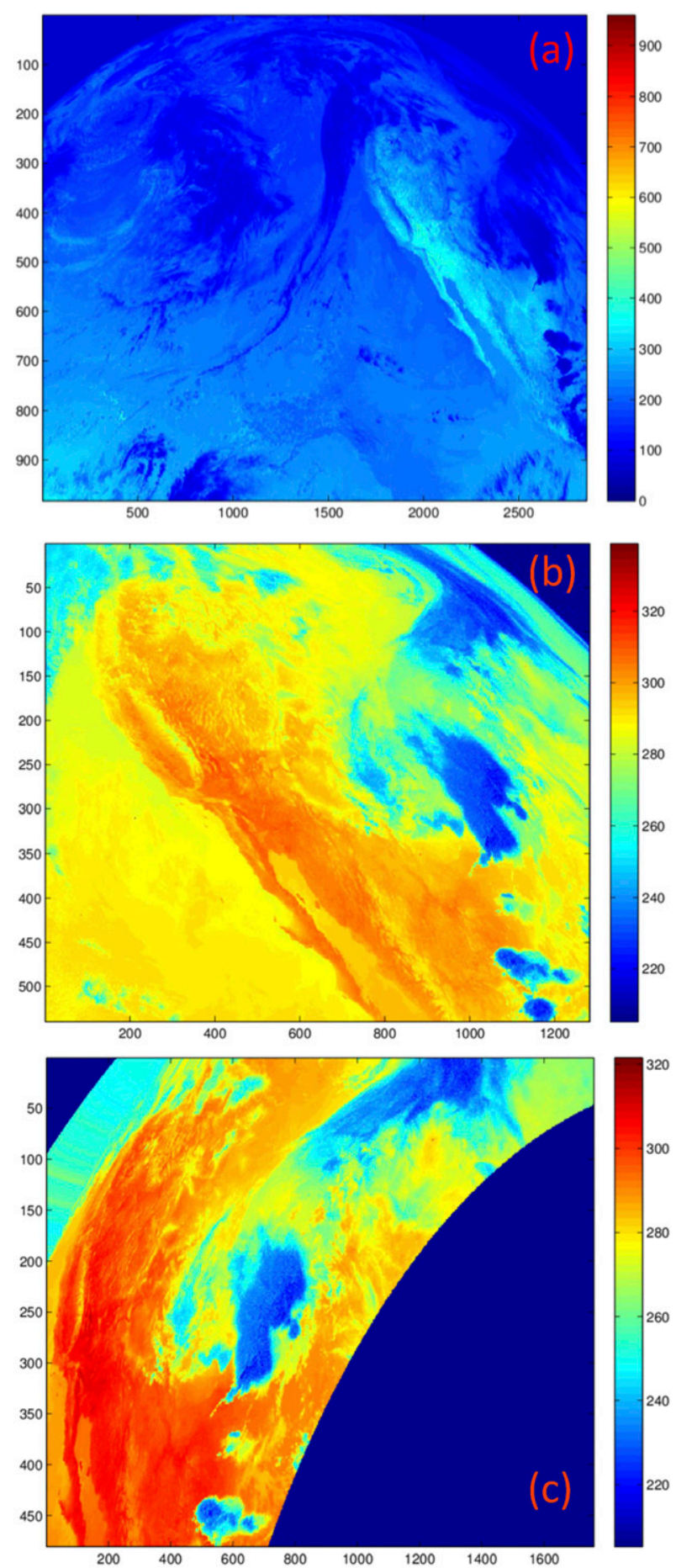

FIG. 1. (a) Band 2 image for 0030 UTC 1 May 2000 (raw counts). The $X-Y$ axis shows pixel lines and elements; (b) calibrated band-2 brightness temperature for 0030 UTC 1 May 2000; (c) reprojected GOES-W to GOES-E. done using "nearest neighbor" interpolation method. The reprojected GOES-W image to GOES-E domain is shown in Fig. 1c. To run the LST retrieval algorithm for GOES-W, there is also a need to prepare ancillary data, such as surface type, snow-free channel-1 radiance and a pixel position data information for gridding in the same dimension and location as the satellite images of GOES-W.

\section{c. Data used for evaluation}

\section{MOD11}

The LST retrievals from MOD11 version 6 land surface temperature and emissivity product (Wan 2014) are used to evaluate the GOES-based LST estimates at two time scales (instantaneous and daily). There are two algorithms used to process the MODIS LST: the generalized split-window LST algorithm and the day-night LST algorithm (Wan and Dozier 1996; Wan and Li 1997; Wang et al. 2014). The data are produced as a series of nine products. We use both MOD11_L2 data (DOI: 10.5067/MODIS/MOD11_L2.006) and MOD11C3 data (DOI: 10.5067/MODIS/MOD11C3.006). The MOD11_L2 version 6 swath product (MOD11L2 hereafter) provides LST and emissivity with pixel size of $1 \mathrm{~km}$ in 5 -min temporal increments of satellite acquisition (https://pdaac.usgs.gov/products/ mod11_12v006/). The MOD11C3 version 6 product (hereafter MOD11C3v6) provides monthly LST and emissivity values in a $0.05^{\circ}(5.6 \mathrm{~km}$ at the equator) latitude-longitude climate modeling grid (CMG), which has a geographic grid with 7200 columns and 3600 rows representing the entire globe (https:// lpdaac.usgs.gov/products/mod11c3v006/). The present study is restricted to the continental United States. These two products are also used in Pinker et al. (2019) for a comprehensive comparisons with the GOES-E LST.

\section{d. In situ measurements}

\section{1) SURFRAD/BSRN}

The Surface Radiation Budget Network (SURFRAD) (http:// www.esrl.noaa.gov/gmd/grad/surfrad/) provides the best available, continuous, long-term measurements of surface radiation budget over the United States, which became the continental U.S. contingent of the international Baseline Surface Radiation Network (BSRN) (Ohmura et al. 1998; Augustine et al. 2005). The sites provide upwelling $\left(F_{\mathrm{LW}}^{\uparrow}\right)$ and downwelling $\left(F_{\mathrm{LW}}^{\downarrow}\right)$ longwave radiative fluxes at 1- or 3-min frequency, which makes them suitable for generating LST information that matches well with the GOES LST retrieval time. Used are the Eppley Precision Infrared Pyrgeometers (model PIR), which are sensitive in the spectral range from 3000 to $50000 \mathrm{~nm}$. The general information about the instrumentation can be found online (https://www.esrl.noaa.gov/gmd/grad/surfrad/overview.html). The instrumental error gives rise to an uncertainty in retrieved LST of less than $1 \mathrm{~K}$ (Guillevic et al. 2012). In this paper, we used the site at Desert Rock, Nevada (DRA: $36.62^{\circ} \mathrm{N}$, $\left.116.02^{\circ} \mathrm{W}\right)$, since it is well situated in the overlap domain between the two satellites.

We applied a basic and widely used approach (e.g., Heidinger et al. 2013; Malakar et al. 2018; Martin et al. 2019; Scarino et al. 2017; Yu et al. 2009) to get the LST from the $F_{\mathrm{LW}}^{\uparrow}$ and $F_{\mathrm{LW}}^{\downarrow}$ 

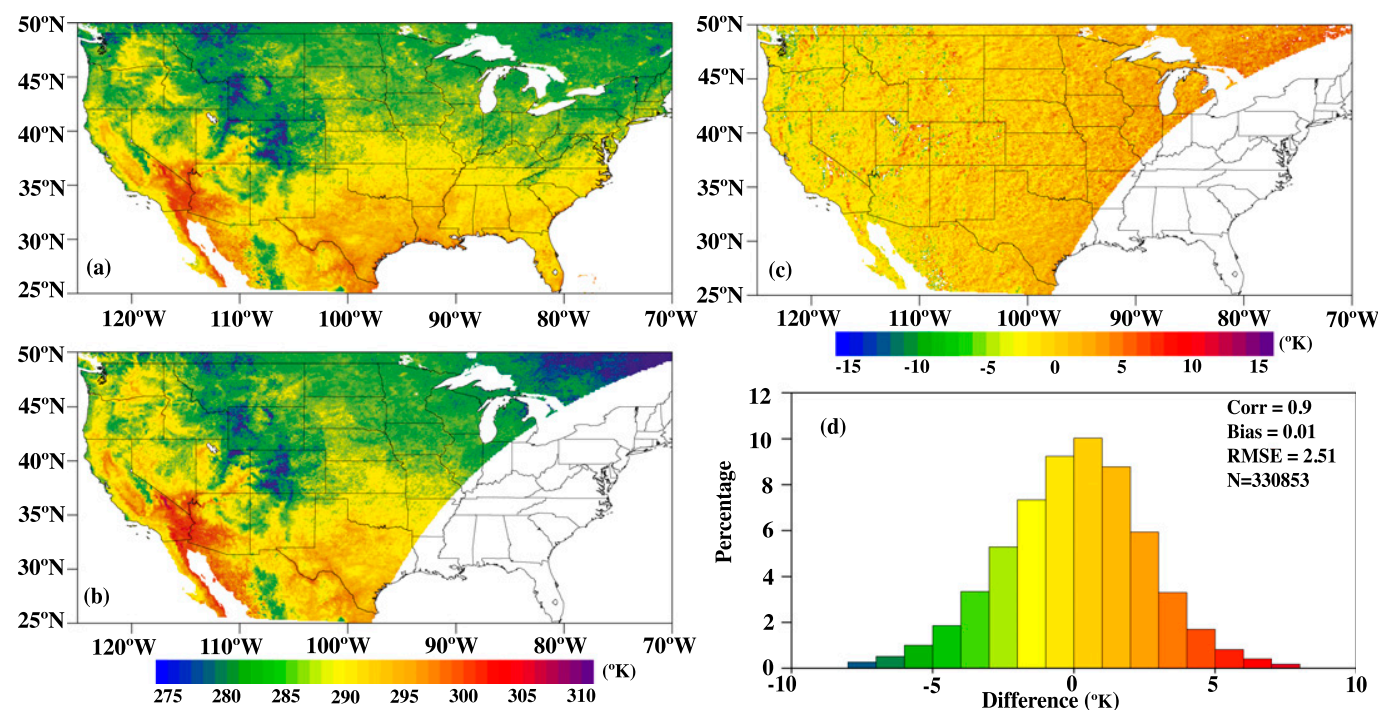

FIG. 2. (a) Monthly mean LST for July 2004 at 0615 UTC retrieved from GOES-E; (b) monthly mean LST for July at 0630 UTC retrieved from GOES-W; (c) LST differences between (a) and (b); (d) frequency distribution of LST differences.

observations. It is based on the Stefan-Boltzmann law, and can be expressed as follows:

$$
\mathrm{LST}=\left\{\left[F_{\mathrm{LW}}^{\uparrow}-\left(1-\varepsilon_{\mathrm{sfc}}\right) F_{\mathrm{LW}}^{\downarrow}\right] /\left(\varepsilon_{\mathrm{sfc}} \sigma\right)\right\}^{1 / 4},
$$

where $\varepsilon_{\text {sfc }}$ is the surface broadband emissivity as provided by CAMEL, and $\sigma$ is the Stefan-Boltzmann constant and is equal to $5.669 \times 10^{-8} \mathrm{~J} \mathrm{~m}^{-2} \mathrm{~s}^{-1} \mathrm{~K}^{-4}$.

\section{2) ARM SOUTHERn Great Plains}

The Southern Great Plains (SGP) atmospheric observatory was the first field measurement site established by the ARM user facility (https://www.arm.gov/capabilities/observatories/ sgp). This observatory is the world's largest and most extensive climate research facility. The SGP site offers high-quality data and simulations at two tower levels (10 and $25 \mathrm{~m})$. The instruments are a Heitronics GmbH KT19.85 Infrared Radiation Pyrometer (https://www.arm.gov/capabilities/instruments/irt) that measure radiances between 9.6 and $11.5 \mu \mathrm{m}$. The temperature resolution is $\pm 0.45 \mathrm{~K}$ at $293 \mathrm{~K}$. The uncertainty is $0.0244 \mathrm{~K}$ for a $0-1 \mathrm{~V}$ output range and $100 \mathrm{~K}$ span. The instruments are checked annually and the data quality is monitored by the ARM Data Quality Office. The surface skin
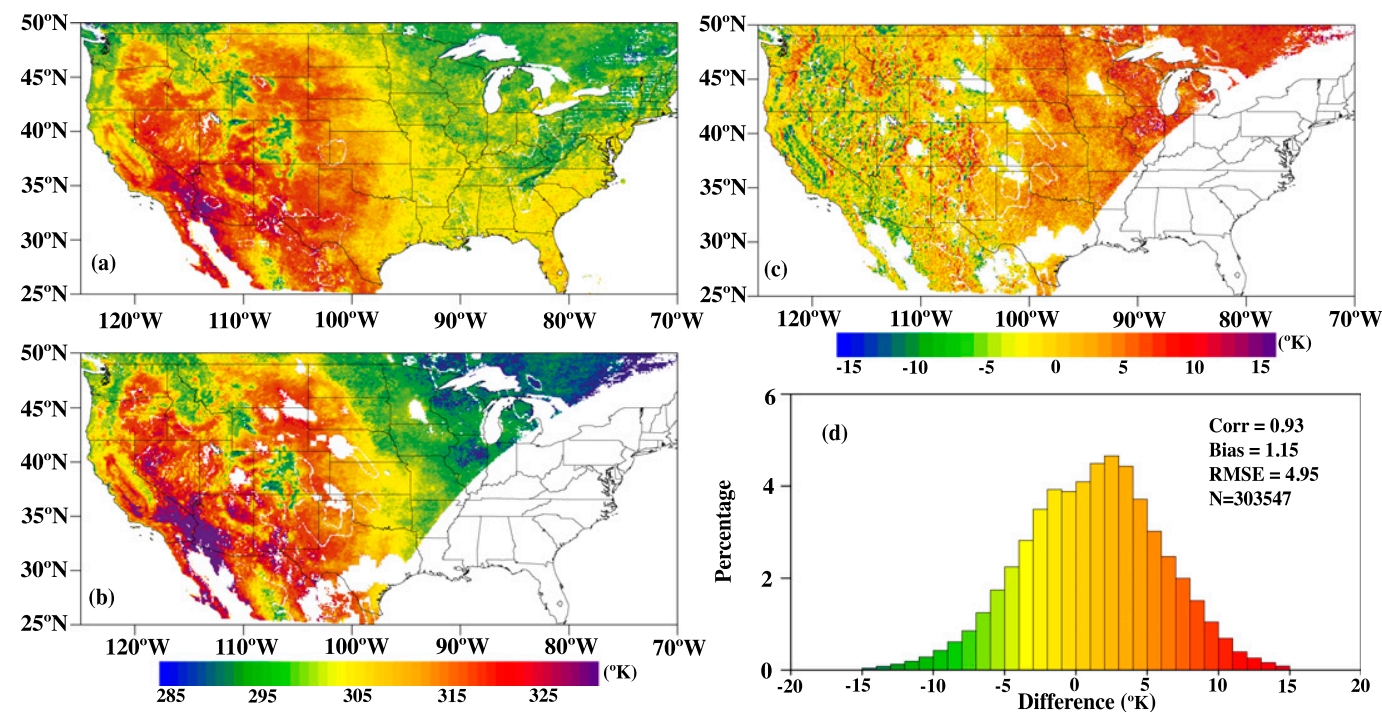

FIG. 3. (a) Monthly mean LST for July 2004 at 1815 UTC retrieved from GOES-E; (b) monthly mean LST for July at 1830 UTC retrieved from GOES-W; (c) LST differences between (a) and (b); (d) frequency distribution of LST differences. Only grids/points that have at least 3 days of values have been used. 

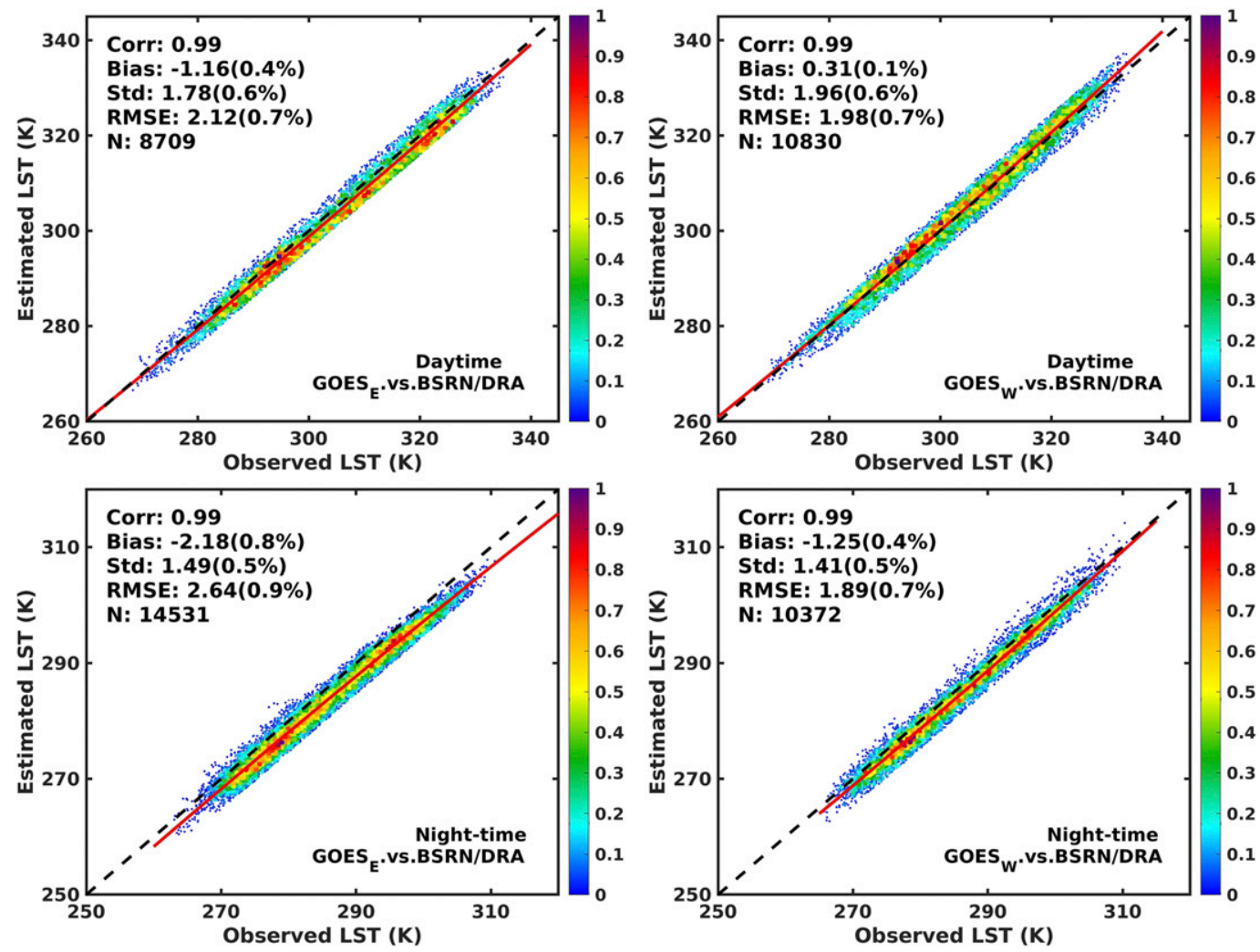

FIG. 4. Evaluation of instantaneous (left) GOES-E- and (right) GOES-W-based LST estimates against the DRA station, independently for (top) daytime and (bottom) nighttime from 2004 to 2009.

temperature used in this paper is observed at 60 -s intervals at the Central Facility $\left(36.60^{\circ} \mathrm{N}, 97.48^{\circ} \mathrm{W}\right)$.

\section{3) OKLahoma Mesonet}

As detailed in Pinker et al. (2019) the Oklahoma Mesonet is a world-class network of environmental monitoring stations (http://www.mesonet.org). The network was designed and implemented by scientists from the University of Oklahoma (OU) and Oklahoma State University (OSU). It is an automated network of 120 stations across Oklahoma. About eighty nine of the Mesonet sites are installed with infrared temperature (IRT) sensors $(8-14 \mu \mathrm{m})$ (Apogee Instruments, Inc.). This sensor is water resistant, designed for continuous outdoor use. Sensor accuracy is approximately $\pm 0.2 \mathrm{~K}$ from 288 to $308 \mathrm{~K}$ and $\pm 0.3 \mathrm{~K}$ from 278 to $318 \mathrm{~K}$. The sensors are installed at a height of $1.5 \mathrm{~m}$ and have a field of view of a diameter circle of $0.5 \mathrm{~m}$. A combination of automated and manual tests are applied using simultaneous soil and atmospheric measurements to intercompare observations and ensure that the skin temperature observations are of research quality (Fiebrich et al. 2003).

\section{e. Uncertainties}

The primary uncertainties of ground-based LST retrievals depend on the accuracy of the radiometric measurements and the emissivity estimates used in Eq. (2) (e.g., Hook et al. 2004, 2007, 2020; Augustine and Dutton 2013; Heidinger et al. 2013;
Guillevic et al. 2014, 2017; Sobrino and Skoković 2016; Göttsche and Hulley 2012; Göttsche et al. 2013, 2016; Martin et al. 2019). The error in the in situ LST caused by the uncertainty of upwelling $\left( \pm 5 \mathrm{~W} \mathrm{~m}^{-2}\right)$ and downwelling $\left( \pm 5 \mathrm{~W} \mathrm{~m}^{-2}\right)$ radiometric measurement is less than $0.2 \mathrm{~K}$ (Martin et al. 2019). Error introduced by uncertainty in the broadband emissivity $(<0.1)$ is less than $0.25 \mathrm{~K}$ (Heidinger et al. 2013). It should be noted that the above referenced errors are not negligible but neither are they a major source of uncertainty in LST estimation. Sobrino and Skoković (2016) claim that "the biggest part of uncertainty is due to inhomogeneity, which varies for each station and season. The other components have less influence, especially in seasons where the inhomogeneity is high." The homogeneity of each site was previously assessed in Pinker et al. (2019). It was found that these sites showed a high degree of homogeneity for the period of $2000-08$ over a $0.05^{\circ} \times$ $0.05^{\circ}$ box.

\section{f. Matchup issues}

The method of spatial and temporal matching is described in Pinker et al. (2019) for GOES-E and also used for GOES-W. Briefly, since the spatial scale of the ground-based LST and the satellite LST product is different, we averaged the pixel values that fall within a $0.05^{\circ} \times 0.05^{\circ}$ box, with the target site as a center. To reduce time difference between the in situ and satellite-based LST, we took the averages of the in situ LST observations that fall in \pm 15 min interval around the start of the scanning time for 

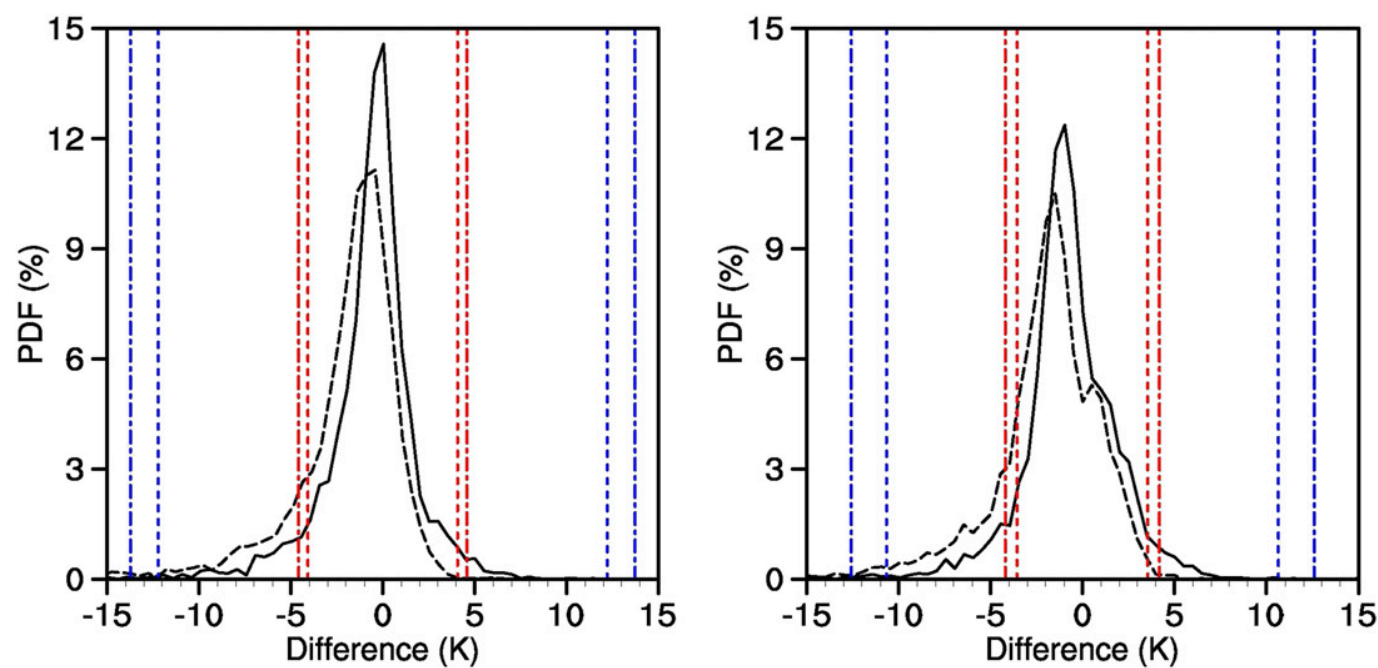

FIG. 5. Evaluation of GOES-E and GOES-W against ARM/SGPC1 at (left) 10 and (right) 25 m during $2004-09$. Black solid: GOES-E; black dashed: GOES-W; red dotted: \pm std for GOES-E; blue dotted: \pm 3 std for GOES-E; red dash-dotted: \pm 1 std for GOES-W; blue dash-dotted: \pm 3 std for GOES-W.

each GOES satellite. This selection is based on the scan duration (10-15 min) of the GOES satellite operation.

\section{Results}

\section{a. Evaluation of LST from GOES-E and GOES-W}

As discussed in sections $2 \mathrm{a}$ and $2 \mathrm{~b}$, required changes have been implemented in the retrieval schemes for applicability to GOES-W. The RTTOV algorithm is run for GOES-E and GOES-W for the years of 2004-09. The retrieved results from GOES-E for July 2004 at 0615 UTC and from GOES-W for July 2004 at 0630 UTC were compared against each other as shown in Fig. 2. Their differences and the frequency distribution of these differences are also illustrated. The frequency distribution of LST differences between the monthly means is also given. As seen, in the overlap area, the LST has similar spatial distribution patterns. The mean and median value of differences are small, 0.01 and $0.11 \mathrm{~K}$, respectively.

In Fig. 3 we show monthly mean LST for July 2004 at 1815 and 1830 UTC as retrieved from GOES-E and GOES-W, respectively, and their difference. The frequency distribution of LST differences is also given. As seen, the differences are higher than at 0600 UTC, the mean and median value of differences are 0.15 and $1.33 \mathrm{~K}$, respectively. The objective of this evaluation was to provide information on the range of differences during extreme times of the day.

\section{b. Evaluation against SURFRAD/BSRN at DRA}

We have evaluated GOES-E and GOES-W LST estimates at DRA for the period 2004-09, independently for daytime and nighttime. The scatterplots of the instantaneous satellite-based LST for GOES-E and GOES-W against DRA for both daytime and nighttime from 2004 to 2009 are shown in Fig. 4. As evident, the satellite estimates and the ground observations have high correlation (Corr $\approx 0.99$ ). Overall, GOES-W has smaller bias than GOES-E for both daytime and nighttime. For daytime (upper panel, Fig. 4) the bias of GOES-W is about $0.31 \mathrm{~K}(0.1 \%)$ while GOES-E is about $-1.16 \mathrm{~K}(0.4 \%)$. For nighttime, the bias is $-1.25 \mathrm{~K}(0.4 \%)$ and $-2.18 \mathrm{~K}(0.8 \%)$ for GOES-W and GOES-E, respectively. The standard deviation (std) of the two products are comparable to each other for both daytime and nighttime ( $\mathrm{std}<2 \mathrm{~K}$ ). The root-mean-square error (RMSE) is less than $1 \%$. One needs to note that the GOESE instantaneous LST we used here are $15 \mathrm{~min}$ after hour while the GOES-W instantaneous data are $30 \mathrm{~min}$ after the hour. However, the averaging of the ground observations are around each satellite overpass time, respectively.

\section{c. Comparison between GOES-E, GOES-W at instanta- neous time scale over the ARM/SGPC1 site}

The probability distribution of differences between GOESE and GOES-W-based LST retrievals and ARM/SGPC1 in situ LST is shown in Fig. 5 and statistics are provided in

TABLE 3. Statistics from intercomparison of LST retrieved from GOES-E and GOES-W at the ARM/SGPC1 site during 2004-09 as shown in Fig. 5.

\begin{tabular}{|c|c|c|c|c|c|c|c|c|}
\hline & \multicolumn{2}{|c|}{ Corr } & \multicolumn{2}{|c|}{ Bias } & \multicolumn{2}{|c|}{ Std } & \multicolumn{2}{|c|}{ RMSE } \\
\hline & GOES-E & GOES-W & GOES-E & GOES-W & GOES-E & GOES-W & GOES-E & GOES-W \\
\hline $10 \mathrm{~m}$ & 0.96 & 0.95 & $-0.74(0.25 \%)$ & $-2.04(0.71 \%)$ & $4.07(1.41 \%)$ & $4.57(1.58 \%)$ & $4.14(1.43)$ & $5.01(1.73 \%)$ \\
\hline $25 \mathrm{~m}$ & 0.97 & 0.96 & $-0.92(0.32 \%)$ & $-2.22(0.77 \%)$ & $3.55(1.23 \%)$ & $4.19(1.45 \%)$ & $3.67(1.27 \%)$ & $4.75(1.64 \%)$ \\
\hline
\end{tabular}



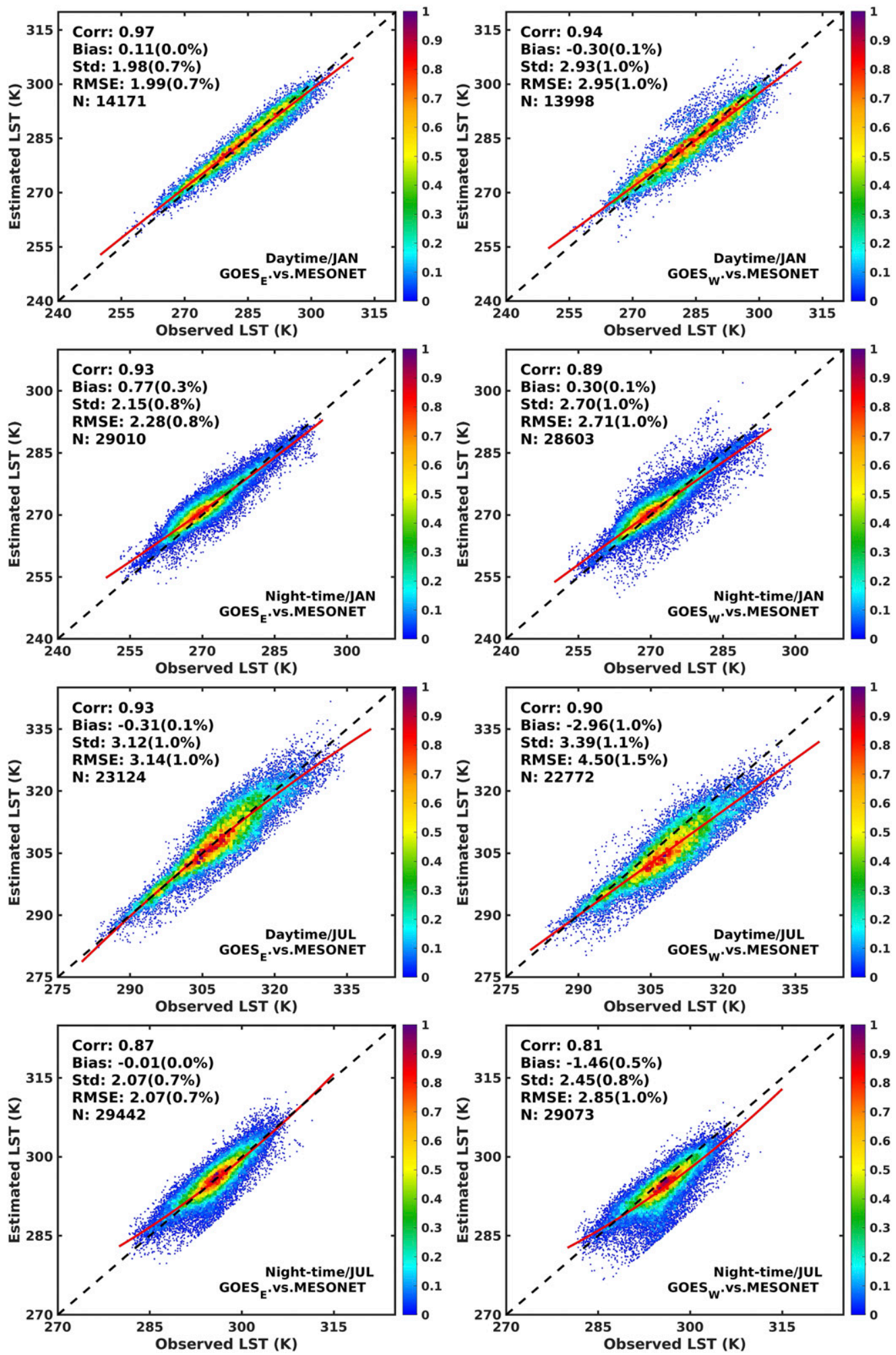

FIG. 6. Evaluation against Mesonet sites for daytime and nighttime in January and July over 2004-07. 

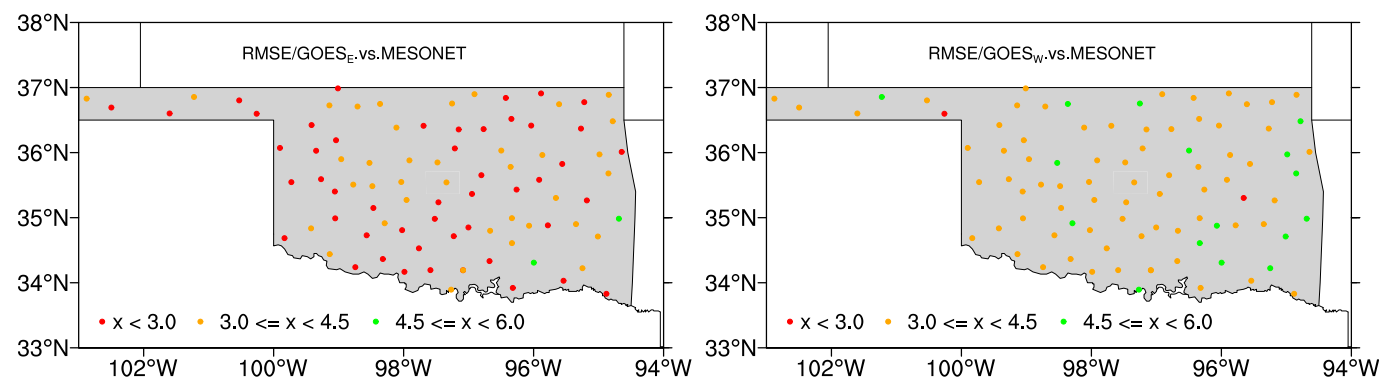

FIG. 7. Distribution of RMSE from intercomparison of LST retrieved from (left) GOES-E and (right) GOES-W at Mesonet sites during 2004-07.

Table 3. Most of the differences $(>80 \%)$ fall within the interval of 1 std $(\sim 4 \mathrm{~K})$. The correlation between GOES-E and ARM/SGPC1 and GOES-W and ARM/SGPC1 is high for both observational levels (Corr $>0.95$ ). The bias for GOES-E at 10 and $25 \mathrm{~m}$ is about $-0.74 \mathrm{~K}(0.25 \%)$ and $-0.92 \mathrm{~K}(0.32 \%)$, respectively, while GOES-W is about $1.3 \mathrm{~K}$ lower.

\section{d. Comparison between GOES-E, GOES-W at instanta- neous time scale at Oklahoma Mesonet}

The distribution of Oklahoma Mesonet sites used in current evaluation is shown (Fig. 7). The evaluations are carried out against all the stations for both daytime and nighttime in January and July during 2004-07. Results are presented in Figs. 6 and 7 . Both of the retrieved GOES LSTs have high correlation with the in situ data (Corr $>0.8$ ); see Table 4 . Results for GOES-E at both daytime and nighttime for January and July are comparable. GOES-W has smaller bias for July than January at both daytime and nighttime. For January, the GOES-W data have comparable bias with GOES-E, but relatively have a larger spread than GOES-E. For July, the bias of GOES-E data is much smaller than GOES-W and its spread is also slightly smaller than GOES-W.

Figure 7 shows the distribution of RMSE from intercomparison of LST retrieved from GOES-E, GOES-W at Mesonet sites during 2004-07. As seen for GOES-E, the RMSE of most of the sites is less than $1 \%$ of their mean LST $(282.03-298.66 \mathrm{~K})$. Only at two sites the RMSE is greater than $1.5 \%$ but less than $2 \%$. The minimum value is $1.76 \mathrm{~K}$ and the maximum is $6.53 \mathrm{~K}$. For GOES-W, at most of the sites the RMSE is greater than $1 \%$ but less than
$1.5 \%$. The minimum value is $1.92 \mathrm{~K}$ and the maximum is $6.76 \mathrm{~K}$.

\section{e. Comparison between GOES-E, GOES-W, and MODIS at instantaneous time scale}

We have conducted an intercomparison between MOD11L2 and the two GOES LST estimates. The intercomparison approach requires accounting for differences in spatial resolution, view angle and overpass time between the satellites (Guillevic et al. 2014). Matchups represent coincident pairs of granules with respect to satellite overpass times and view angles. The "near miss" time spans are usually referred to as simultaneous nadir overpasses (SNOs) when nadir view angles are considered (Cao et al. 2004). First, the MOD11L2 data are regridded to $0.05^{\circ} \times 0.05^{\circ}$. The GOES-W LST has a $15 \mathrm{~min}$ time difference with GOES-E and MODIS. Figure 8 shows the LST retrievals from GOES-E and MOD11L2 at 1815 UTC and GOES-W at 1830 UTC 29 August 2004. The differences of their distributions are presented in Fig. 9. The statistics are based on all available grid points for this case as shown in Table 5 .

As seen in the left panel of Fig. 8, the highest LST is close to the southeast coast for all of the three products. The maximum values for GOES-E, GOES-W, and MOD11L2 are 332.2, 334.7, and $332.7 \mathrm{~K}$, respectively. The position of lowest LST for all three products are similarly located. The minimum values are $278.8,269.0$ and $280.9 \mathrm{~K}$. As evident from the right panel of Fig. 8, most of the grids are in the range of 307.5-313.0 K for all products.

From Fig. 9 and Table 5, it is evident that both GOES LST products have high correlation with MOD11L2 (coefficients are over 0.85 using more than 40000 grid points) while GOES

TABLE 4. Statistics from intercomparison of LST retrieved from GOES-E, GOES-W at Mesonet sites for daytime and nighttime in January and July over 2004-07.

\begin{tabular}{|c|c|c|c|c|c|c|c|c|c|}
\hline & & \multicolumn{2}{|c|}{ Corr } & \multicolumn{2}{|c|}{ Bias } & \multicolumn{2}{|c|}{ Std } & \multicolumn{2}{|c|}{ RMSE } \\
\hline & & GOES-E & GOES-W & GOES-E & GOES-W & GOES-E & GOES-W & GOES-E & GOES-W \\
\hline \multirow[t]{2}{*}{ January } & Day & 0.97 & 0.94 & $0.11(0.0 \%)$ & $-0.3(0.1 \%)$ & $1.98(0.7 \%)$ & $2.93(1.0 \%)$ & $1.99(0.7 \%)$ & $2.95(1.0 \%)$ \\
\hline & Night & 0.93 & 0.89 & $0.77(0.3 \%)$ & $0.3(0.1 \%)$ & $2.15(0.8 \%)$ & $2.7(1.0 \%)$ & $2.28(0.8 \%)$ & $2.71(1.0 \%)$ \\
\hline \multirow[t]{2}{*}{ July } & Day & 0.93 & 0.90 & $0.31(0.1 \%)$ & $2.96(1.0 \%)$ & $3.12(1.0 \%)$ & $3.39(1.1 \%)$ & $3.14(1.0 \%)$ & $4.5(1.5 \%)$ \\
\hline & Night & 0.87 & 0.81 & $0.01(0.0 \%)$ & $1.46(0.5 \%)$ & $2.07(0.7 \%)$ & $2.45(0.8 \%)$ & $2.07(0.7 \%)$ & $2.85(1.0 \%)$ \\
\hline
\end{tabular}



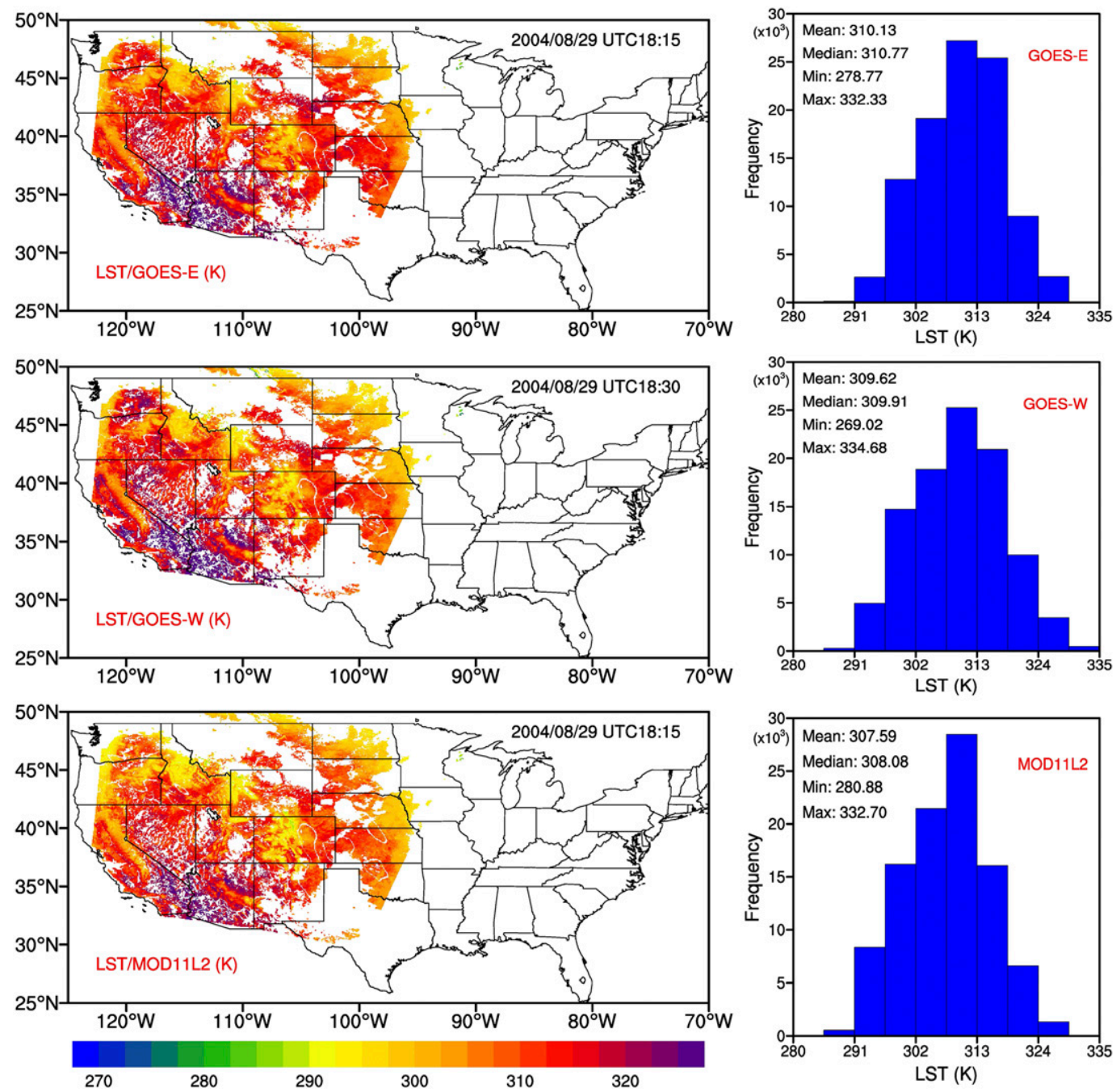

FIG. 8. (left) LST retrievals and (right) their distributions from (bottom) MOD11L2 and (top) GOES-E for 1815 UTC and (middle) GOES-W for 1830 UTC 29 Aug 2004.

LST products are higher than MOD11L2. The largest differences occur in Washington State. The bias for GOES-E and GOES-W is about $2.54 \mathrm{~K}(0.8 \%)$ and $2.03 \mathrm{~K}(0.7 \%)$, respectively. Correlation coefficient between GOES-W and GOES-E LST is 0.9 and the bias is about $-0.51 \mathrm{~K}(0.2 \%)$.

\section{f. Comparison between GOES-E, GOES-W, and MODIS at seasonal time scale}

We also evaluate the ability of capturing the LST seasonal changes at DRA including the MOD11C3v6 product. Figure 10 shows the LST distribution for GOES_E, GOES-W, and MOD11C3v6 over 2004-09 for each month and their monthly mean values compared with DRA (Table 6).

Both of the retrieved GOES LSTs have similar patterns of variability to those from the DRA site. MOD11C3v6 LSTs are higher than the DRA observations for most seasons; the annual mean LST for all years used is $294.5 \mathrm{~K}$, which is $2.3 \mathrm{~K}$ higher than the value measured at DRA (292.2 K), but GOES estimates are much closer to the site value than the others. The annul mean LST from GOES-E is $290.6 \mathrm{~K}$, which is $1.6 \mathrm{~K}$ lower than DRA; the value from GOES-W is $291.5 \mathrm{~K}$, which is $0.7 \mathrm{~K}$ lower than DRA.

\section{g. Climatology of LST}

A 6 yr (2004-09) mean LST at $0.05^{\circ}$ spatial resolution for January and July is shown in Fig. 11; statistics is presented in Table 7. As shown, for July and January, the LST distribution pattern of the two products are similar to each other. They have high correlation (Corr $>0.9)$ and very small bias $(0.19 \mathrm{~K}$ for July and $-0.76 \mathrm{~K}$ for January). The std and RMSE are larger in July than in January.

Figure 12 shows the diurnal cycle of LST at DRA and at the ARM/SGPC1 sites from ground and satellite-based estimates. Closer agreement between the satellite and ground observations is seen from about noon to late afternoon. The difference between DRA observations and GOES estimates are around 

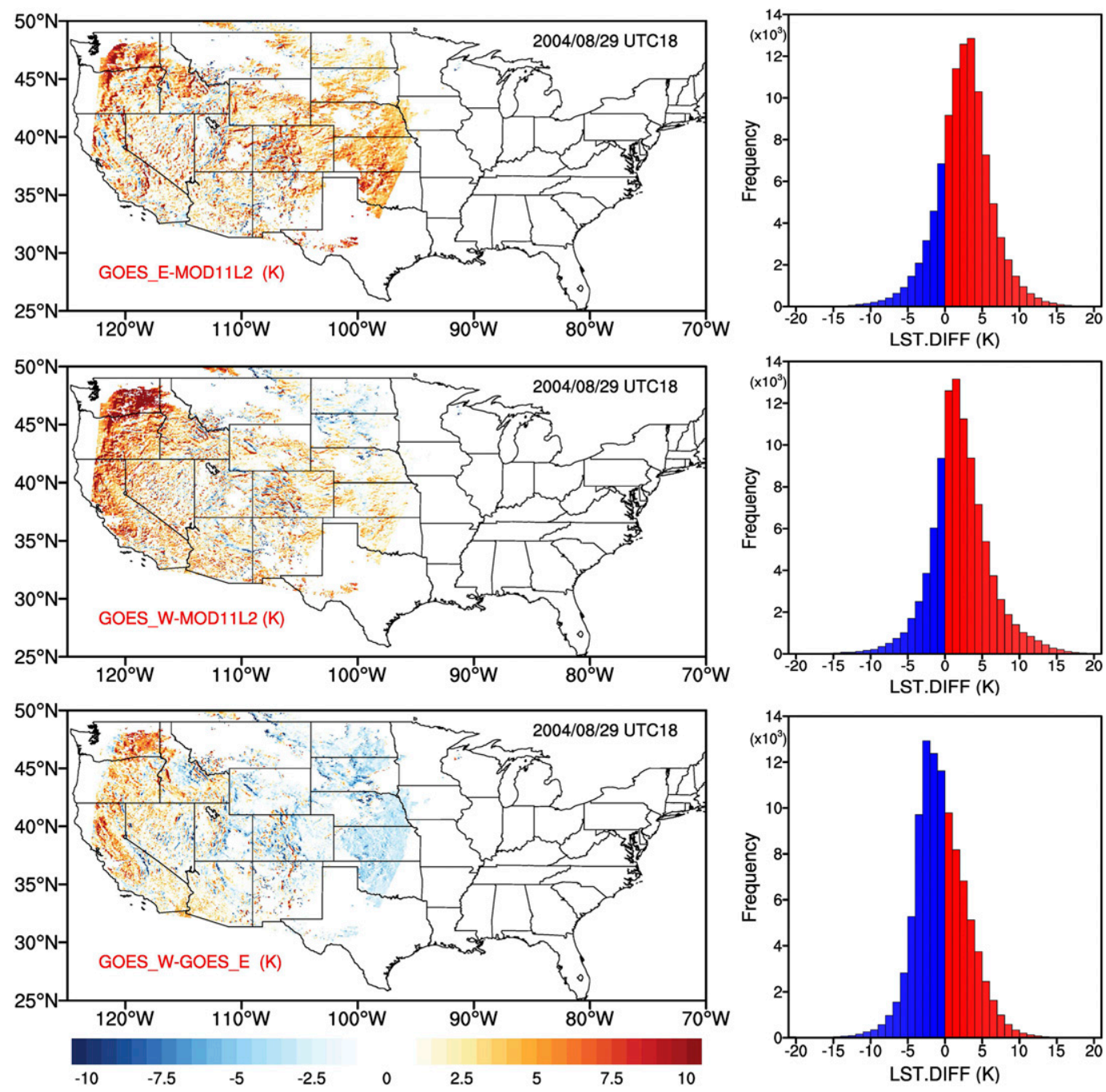

FIG. 9. Comparison of LST retrieval differences between (top) GOES-E and MOD11L2, (middle) GOES-W and MOD11, and (bottom) GOES-E and GOES-W at 1815 or 1830 UTC 29 Aug 2004. The statistical summaries are shown in Table 5.

0-2 $\mathrm{K}$ while at ARM/SGPC1 the differences are about $0.5-3 \mathrm{~K}$; before noon, the differences are larger around $0-6 \mathrm{~K}$. The GOES-E LST has shown a good agreement in depicting the diurnal cycle at other SURFRAD sites (Pinker et al. 2019). These findings indicate that the GOES-E and GOES-W estimates have the ability to represent well the diurnal variations of the LST. This is of extreme interest since most satellitebased estimates of LST use polar orbiters unable to depict the true diurnal cycle. A comprehensive analysis over the entire United States will be conducted independently.

\section{Summary and discussion}

Prospects for achieving global information from GEO satellites are improving. New development in geostationary systems aims to make them more similar to each other in terms of

TABLE 5. Statistics from intercomparison among LST retrieved from GOES-E and GOES-W and from MOD11L2 product at 1815 or 1830 UTC 29 Aug 2004 as shown in Fig. 9.

\begin{tabular}{lccrr}
\hline \hline & Corr & Bias & Std & RMSE \\
\hline GOES_E vs MOD11L2 & 0.88 & $2.54(0.8 \%)$ & $3.74(1.2 \%)$ & $4.52(1.5 \%)$ \\
GOES_W vs MOD11L2 & 0.87 & $2.03(0.7 \%)$ & $4.03(1.3 \%)$ & $4.51(1.5 \%)$ \\
GOES_E vs GOES_W & 0.90 & $-0.51(0.2 \%)$ & $3.58(1.2 \%)$ & $3.62(1.2 \%)$ \\
\hline
\end{tabular}




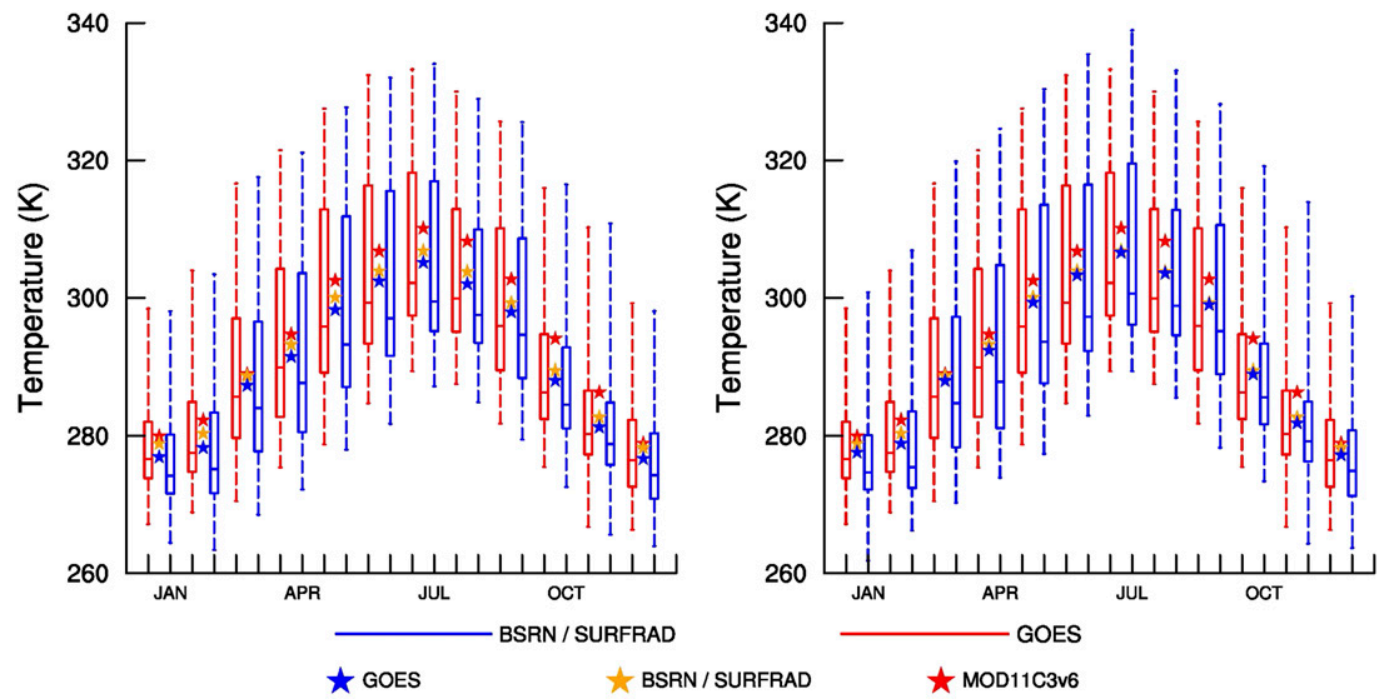

FIG. 10. Comparison of (left) GOES-E and (right) GOES-W LST at monthly time scale for 2004-09 with MOD11C3v6 and the DRA site. The mean values (stars) are shown in Table 6.

spatial resolution and the spectral characteristics of relevant channels. For instance, the GOES-R Advanced Baseline Imager (ABI) Sensor (Schmit et al. 2017) is similar to the Advanced Himawari Imager (AHI) 8 and 9 (Okuyama et al. 2015). Such improvements make it possible to establish a consistent and seamless long-term global record of land surface properties, which requires homogenization of satellite observations from several sources. However, the issue of merging of the observations in areas of overlap due to differences in viewing geometry and the impact of the anisotropy of surface emissivity (Minnis et al. 2004; Cuenca and Sobrino 2004; Pinheiro et al. 2006) still exists. As illustrated in Evan et al. (2007) in respect to the International Satellite Cloud Climatology Project (ISCCP) cloud data (Rossow and Schiffer 1999), the abrupt changes in global cloud amounts result from sudden changes in the geostationary viewing angles. They also point out that these observations are consistent with the theory that changes in the number of geostationary satellites are altering information on the global mean cloud amounts (Campbell 2004). As such it is critical to evaluate and optimize observations from different sources, a formidable task and as yet, not comprehensively addressed. An early attempt to address the merging issue from geostationary satellites in respect to surface radiative fluxes is described in Zhang et al. (2007). They introduced a semiempirical orthogonal function (EOF) iteration scheme for homogenizing the fluxes. On the average, the latter reduced the RMSE in the fluxes as compared to ground observations by about $2-3 \mathrm{~W} \mathrm{~m}^{-2}$. The newly revived interest in the topic of merging GEO satellite observations can be attributed to progress made to improve satellite observations. The new capabilities of geostationary satellites (the European SEVIRI, ABI on GOES-R, Himawari-8/9) provide new capabilities to derive high-resolution (temporal and spatial) climatic parameters such as LST. The satellites have similar channels (GOES-R and Himawari-8/9), which reduces some of the problems in merging data from different platforms.
In this paper, we describe an approach to derive and evaluate high-temporal- and high-spatial-resolution information on LST from the GOES satellites across multiple missions and multiple sensors with overlapping coverage. Specifically, we have implemented the RTTOV radiative transfer model adjusted for channel $4(10.7 \mu \mathrm{m})$ of GOES-E and GOES-W with the MERRA-2 atmospheric profiles and the CAMEL emissivity product to derive a 6 yr record (2004-09) of LST. The data are produced at $0.05^{\circ}$ spatial resolution at hourly time scale and evaluated for the period of 2004-09 against best available ground observations and an independent well established product from MODIS. We report results of evaluation at instantaneous time scale as well as averaged over a month. We found that monthly mean differences in LST for July at 0600 UTC retrieved from GOES-E and GOES-W in terms of mean and median values were 0.01 and $0.11 \mathrm{~K}$, respectively, but were higher at $1800 \mathrm{UTC}$, with respective mean and median differences of 0.15 and $1.33 \mathrm{~K}$. The

TABLE 6. Mean LST for each month from GOES-E, GOES-W, MOD11C3v6, and DRA as shown in Fig. 8.

\begin{tabular}{lcccc}
\hline \multicolumn{1}{c}{ Month } & DRA & GOES-E & GOES-W & MOD11C3v6 \\
\hline January & 278.975 & 277.033 & 277.721 & 279.745 \\
February & 280.479 & 278.379 & 278.997 & 280.39 \\
March & 288.849 & 287.462 & 288.138 & 291.827 \\
April & 293.308 & 291.565 & 292.476 & 295.192 \\
May & 300.195 & 298.384 & 299.454 & 302.322 \\
June & 304.02 & 302.528 & 303.432 & 307.414 \\
July & 306.958 & 305.266 & 306.715 & 309.732 \\
August & 303.918 & 302.154 & 303.678 & 307.302 \\
September & 299.406 & 298.055 & 299.128 & 302.197 \\
October & 289.594 & 288.165 & 289.098 & 294.88 \\
November & 282.815 & 281.377 & 281.987 & 283.123 \\
December & 278.397 & 276.798 & 277.329 & 280.16 \\
Avg & 292.243 & 290.597 & 291.513 & 294.524 \\
\hline
\end{tabular}



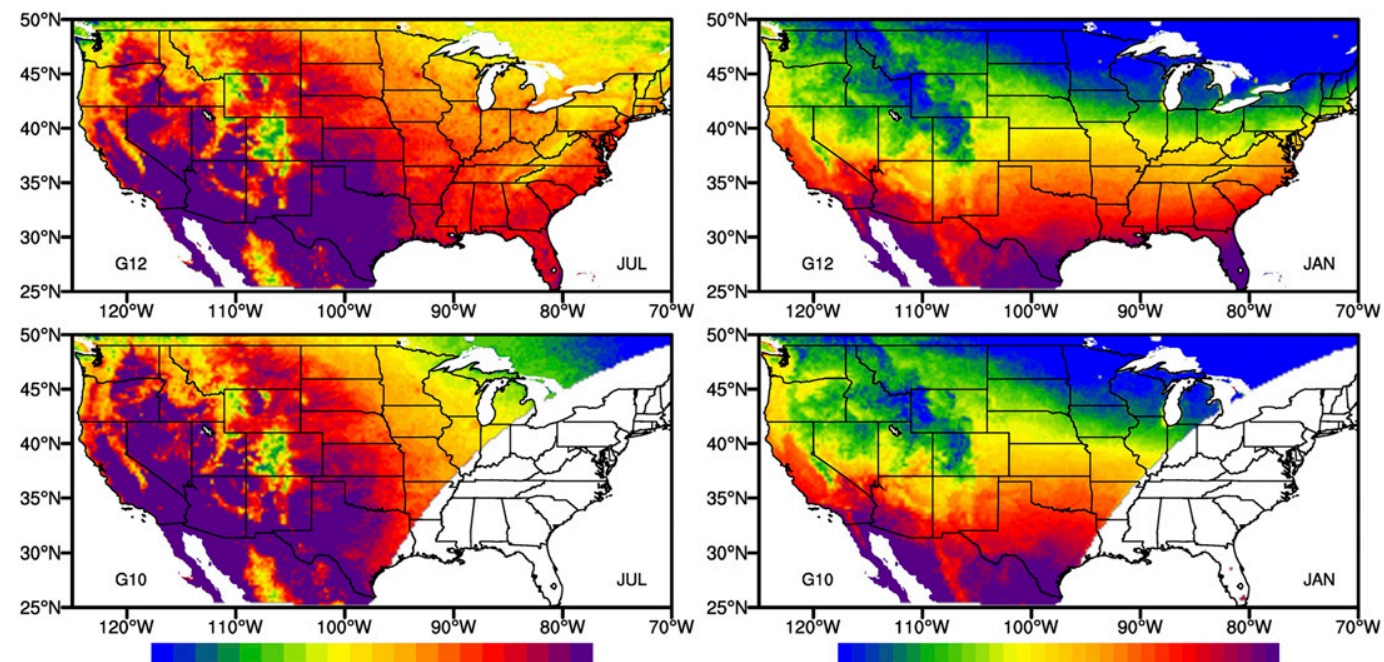

$\begin{array}{llllllllll}282 & 284 & 286 & 288 & 290 & 292 & 294 & 296 & 298 & 300\end{array}$
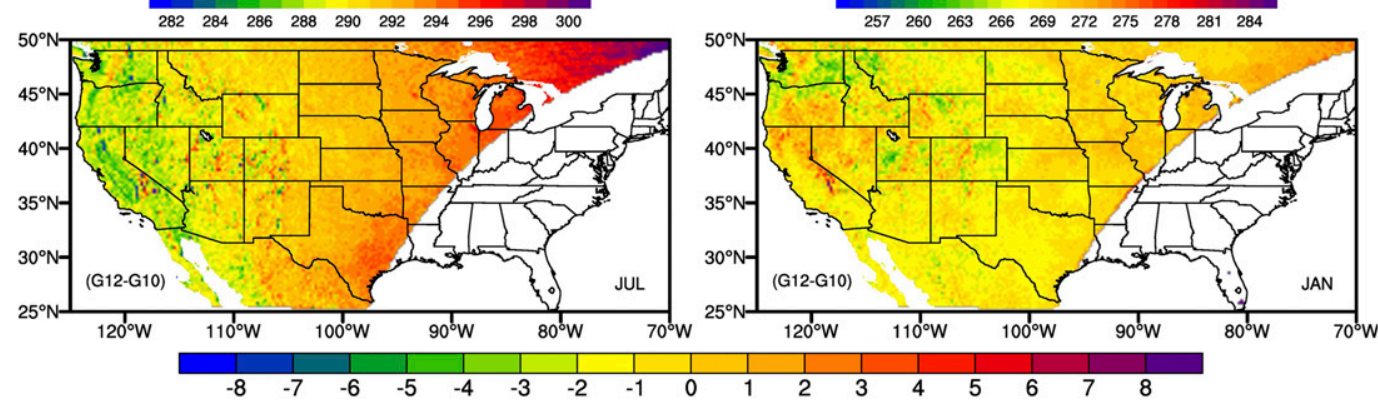

FIG. 11. Climatology of LST for (left) July and (right) January averaged for 2004-09 as derived from (top) GOES-EAST and (middle) GOES-WEST and (bottom) their differences.

performance of GOES-based LST is comparable to the MODIS product and is in good agreement with in situ data. As such they are of sufficient quality to represent seasonal and diurnal variability and climatological characteristics of LST over the United States.

The importance of the LST diurnal changes has been amply recognized and a wide range of attempts have been made to estimate it (e.g., Dai and Trenberth 2004; Aires et al. 2004; Sun et al. 2006; Duan et al. 2014). Early studies have demonstrated that there is a strong connection between soil moisture and soil surface temperature. This concept served as a basis for the Heat Capacity Mapping Mission (HCMM) that was the first of NASA's Applications Explorer Missions operational from April 1978 to September 1980 (Taranik and Settle 1981; Price 1977). The satellite was placed in a circular sunsynchronous orbit, allowing the spacecraft to sense surface temperatures near the maximum and minimum of the diurnal cycle to determine the thermal inertia as explained in Idso et al. (1976). Namely, the amplitude of the diurnal surface temperature wave of the soil is a function of (among others), thermal conductivity $(\lambda)$, density $(\rho)$, and specific heat $(c)$ defined as

$$
P=(\lambda \rho c)^{1 / 2}
$$

Idso et al. (1976) have shown that the thermal inertia is inversely proportional to the amplitude of the diurnal surface temperature wave. Carlson (1986) pointed out that the early morning heating rate change can be used as an indicator of soil surface moisture. It was also hypothesized that the moisturetemperature relationship can be utilized to correct prediction of surface temperature by minimizing the difference between simulated and observed skin temperature by adjusting the soil moisture in the model in particular, during the morning period when the heating rate is strong (Barkan et al. 2020). In most cases, the DTR has been estimated from polar orbiting satellites with daytime and nighttime observations. Yet, these do not coincide with the minimum and maximum values of the day. While specific geostationary satellite have been used to derive LST at hourly time scales using a wide range of methods, there is a need in such information at global scale that requires to merge several geostationary satellites to represent the DTR.

Another important application of the DTR as provided by the data that generated in this study is related to issues of

TABLE 7. Intercomparison statistics of LST from GOES-E and GOES-W climatology during 2004-09 over the United States in areas of overlap in January and July.

\begin{tabular}{lcrcc}
\hline \hline & Corr & \multicolumn{1}{c}{ Bias } & Std & RMSE \\
\hline July & 0.93 & $0.19(0.1 \%)$ & $2.39(0.8 \%)$ & $2.4(0.8 \%)$ \\
January & 0.99 & $-0.76(0.3 \%)$ & $1.42(0.5 \%)$ & $1.6(0.6 \%)$ \\
\hline
\end{tabular}




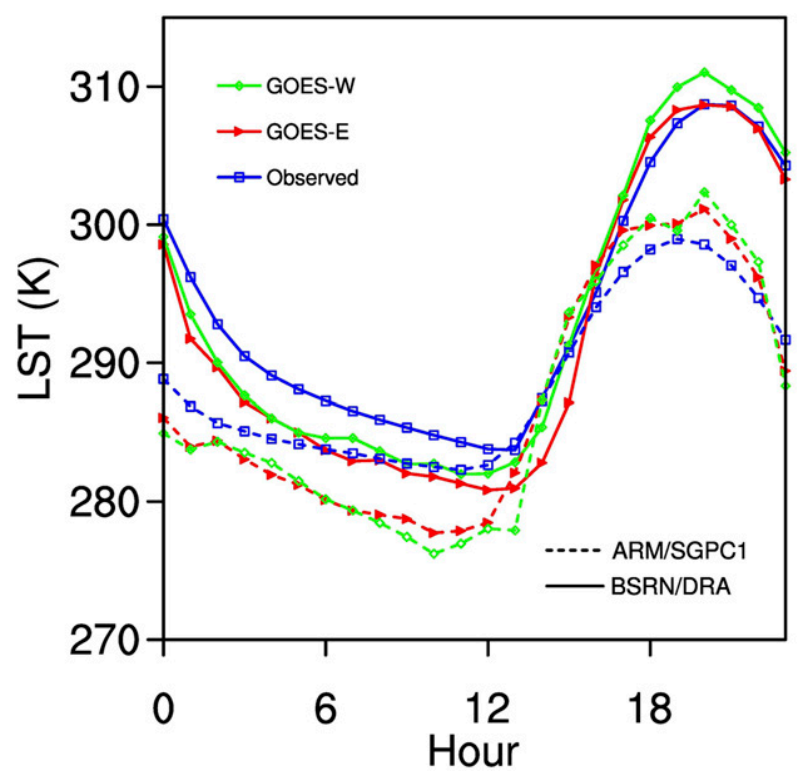

FIG. 12. Diurnal cycle of average LST based on data from 2004 to 2009 as observed at DRA, ARM/SGPC1 and derived from GOESE and GOES-W.

climate change that currently are investigated by changes in mean temperature. According to several studies (Easterling et al. 1997; Dai et al. 1999; Davy et al. 2017) the DTR has been decreasing worldwide since the 1950s. According to Easterling et al. (1997) the decrease is primarily due to the increase in minimum temperature. The various possible causes for the increase in the minimum temperature have been discussed in numerous papers (Karl et al. 1993; Braganza et al. 2004; Stone and Weaver 2002, 2003; Dai et al. 1999). While the above studies used information on air temperature only, the LST data generated allow us to take a fresh look at this issue. As demonstrated, our results are of sufficient quality to represent seasonal and diurnal variability and climatological characteristics of LST over the United States as well as DTR.

Our findings can serve as guidelines for developing a strategy for global coverage from geostationary satellites. The methodology we use minimizes differences between satellites in areas of overlap. The proposed semiempirical corrections for viewing geometry that have been used in a previous study (Scarino et al. 2017) had only small impact on our results. Scarino et al. (2017) found a larger impact of the angular corrections on the retrieved LSTs; however, their experiment is based on independent observations and methodology. Possibly, findings can be also impacted by the limited database used for developing the angular corrections. A controlled experiment using same observations but independent methodology could shed more light on this issue in future.

Acknowledgments. We acknowledge the MERRA-2 data as provided by the Global Modeling and Assimilation Office (GMAO). Information from the MOD11_L2: MODIS/Terra land surface temperature and emissivity 5-min L2 swath $1 \mathrm{~km}$ V006 database (Zhengming Wan, PI), (https:// search.earthdata.nasa.gov/search/granules/collectiondetails? $\mathrm{p}=\mathrm{C} 194001236-\mathrm{LPDAAC} \_$ECS\&m $=-26.4375 ! 136.6875 ! 0 ! 1$ ! $0 ! 0 \% 2 \mathrm{C} 2 \& \mathrm{tl}=1515438649$ ! 4 !! \&q=MOD11_L2\%20V006) was provided under the courtesy of the NASA EOSDIS Land Processes Distributed Active Archive Center (LP DAAC), USGS/Earth Resources Observation and Science (EROS) Center, Sioux Falls, South Dakota. GOES data were obtained from the NOAA Comprehensive Large Array data Stewardship System (CLASS) (https:/www.bou.class.noaa.gov/saa/products/ search?sub_id $=0 \&$ datatype_family $=$ GVAR_IMG\&submit. $=25 \&$ submit.y=8). The BSRN/SURFRAD data were provided by the NOAA Earth System Research Laboratory, Global Monitoring Division (https://www.esrl.noaa.gov/gmd/grad/surfrad/). The ARM data were obtained from the Radiation Measurement (ARM) Climate Research 10.5067/MEaSUREs/LSTE/CAM5K30EM.001. The Mesonet data were provided by https://weather.ok.gov/ index.php/site/about/data_access_and_pricing (McPherson et al. 2007). The team efforts in generating and providing all the required data is greatly appreciated. This research was funded by Grant NNH12ZDA001N-MEASURES from NASA to JPL. Part of the research described in this paper was carried out at the Jet Propulsion Laboratory, California Institute of Technology, under contract with the National Aeronautics and Space Administration. Government sponsorship acknowledged. We thank the anonymous reviewers for constructive comments that helped to improve the manuscript and to the editor for overseeing the review process.

Data availability statement. The data are being prepared for publication on a website. Prior to formal publication can be obtained upon request.

\section{REFERENCES}

Ackerman, T. P., T. S. Cress, W. Ferrell, J. H. Mather, and D. D. Turner, 2016: The programmatic maturation of the ARM program. The Atmospheric Radiation Measurement (ARM) Program: The First 20 Years, Meteor. Monogr., No. 57, Amer. Meteor. Soc., https://doi.org/10.1175/AMSMONOGRAPHSD-15-0054.1.

Aires, F., C. Prigent, and W. B. Rossow, 2004: Temporal interpolation of global surface skin temperature diurnal cycle over land under clear and cloudy conditions. J. Geophys. Res., 109, D04313, https://doi.org/10.1029/2003JD003527.

Anderson, M. C., J. M. Norman, J. R. Mecikalski, J. A. Otkin, and W. P. Kustas, 2007: Climatological study of evapotranspiration and moisture stress across the continental United States: 1. Model formulation. J. Geophys. Res., 112, D10117, https:// doi.org/10.1029/2006JD007506.

— , and Coauthors, 2011: Mapping daily evapotranspiration at field to continental scales using geostationary and polar orbiting satellite imagery. Hydrol. Earth Syst. Sci., 15, 223-239, https://doi.org/10.5194/hess-15-223-2011.

Augustine, J. A., and E. G. Dutton, 2013: Variability of the surface radiation budget over the United States from 1996 through 2011 from high-quality measurements. J. Geophys. Res. Atmos., 118, 43-53, https://doi.org/10.1029/ 2012JD018551. 
G. B. Hodges, C. R. Cornwall, J. J. Michalsky, and C. I. Medina, 2005: An update on SURFRAD: The GCOS Surface Radiation Budget network for the continental United States. J. Atmos. Oceanic Technol., 22, 1460-1472, https://doi.org/ 10.1175/JTECH1806.1.

Barkan, J., H. Shafir, and P. Alpert, 2020: Multi-factor analysis of DTR variability over Israel in the sea/desert border. Theor. Appl. Climatol., 139, 287-295, https://doi.org/10.1007/s00704019-02958-x.

Becker, F., and Z. Li, 1990: Towards a local split window method over land surfaces. Int. J. Remote Sens., 11, 369-393, https:// doi.org/10.1080/01431169008955028.

— various scales: Definition, measurement and related problems. Remote Sens. Rev., 12, 225-253, https://doi.org/10.1080/ 02757259509532286.

Borbas, E., G. Hulley, M. Feltz, R. Knuteson, and S. Hook, 2018: The Combined ASTER MODIS Emissivity over Land (CAMEL) part 1: Methodology and high spectral resolution application. Remote Sens., 10, 643, https://doi.org/10.3390/rs10040643.

Braganza, K., D. J. Karoly, and J. M. Arblaster, 2004: Diurnal temperature range as an index of global climate change during the twentieth century. Geophys. Res. Lett., 31, L13217, https:// doi.org/10.1029/2004GL019998.

Campbell, G., 2004: View angle dependence of cloudiness and the trend in ISCCP cloudiness. 13th Conf. on Satellite Meteorology and Oceanography, Norfolk, VA, Amer. Meteor. Soc., P6.7, https://ams.confex.com/ams/13SATMET/techprogram/paper_ 79041.htm.

Cao, C., M. Weinreb, and H. Xu, 2004: Predicting simultaneous nadir overpasses among polar-orbiting meteorological satellites for the intersatellite calibration of radiometers. J. Atmos. Oceanic Technol., 21, 537-542, https://doi.org/10.1175/15200426(2004)021<0537:PSNOAP>2.0.CO;2.

Carlson, T. N., 1986: Regional scale estimates of surface moisture availability and thermal inertia using remote thermal measurements. Remote Sens. Rev., 1, 197-247, https://doi.org/ 10.1080/02757258609532069.

Cuenca, J., and J. Sobrino, 2004: Experimental measurements for studying angular and spectral variation of thermal infrared emissivity. Appl. Opt., 43, 4598-4602, https://doi.org/10.1364/ AO.43.004598.

Dai, A., and K. E. Trenberth, 2004: The diurnal cycle and its depiction in the Community Climate System Model. J. Climate, 17, 930-951, https://doi.org/10.1175/1520-0442(2004)017<0930: TDCAID $>2.0 . \mathrm{CO} ; 2$.

,-- , and T. R. Karl, 1999: Effects of clouds, soil moisture, precipitation, and water vapor on diurnal temperature range. J. Climate, 12, 2451-2473, https://doi.org/10.1175/ 1520-0442(1999)012<2451:EOCSMP>2.0.CO;2.

Davy, R., I. Esau, A. Chernokulsky, S. Outten, and S. Zilitinkevich, 2017: Diurnal asymmetry to the observed global warming. Int. J. Climatol., 37, 79-93, https://doi.org/10.1002/joc.4688.

Duan, S.-B., Z.-L. Li, B.-H. Tang, H. Wu, R. Tang, Y. Bi, and G. Zhou, 2014: Estimation of diurnal cycle of land surface temperature at high temporal and spatial resolution from clear-sky MODIS data. Remote Sens., 6, 3247-3262, https:// doi.org/10.3390/rs6043247.

Easterling, D. R., and Coauthors, 1997: Maximum and minimum temperature trends for the globe. Science, 277, 364-367, https://doi.org/10.1126/science.277.5324.364.

Ermida, S. L., C. C. DaCamara, I. F. Trigo, A. C. Pires, D. Ghent, and J. Remedios, 2017: Modelling directional effects on re- motely sensed land surface temperature. Remote Sens. Environ., 190, 56-69, https://doi.org/10.1016/J.RSE.2016.12.008.

— I. F. Trigo, C. C. DaCamara, and A. C. Pires, 2018: A methodology to simulate LST directional effects based on parametric models and landscape properties. Remote Sens., 10, 1114, https://doi.org/10.3390/rs10071114.

, G. Hulley, and C. C. DaCamara, 2020: A multi-sensor approach to retrieve emissivity angular dependence over desert regions. Remote Sens. Environ., 237, 111559, https:// doi.org/10.1016/j.rse.2019.111559.

Evan, A. T., A. K. Heidinger, and D. J. Vimont, 2007: Arguments against a physical long-term trend in global ISCCP cloud amounts. Geophys. Res. Lett., 34, L04701, https://doi.org/ 10.1029/2006GL028083.

Feltz, M., E. Borbas, R. Knuteson, G. Hulley, and S. Hook, 2018: The Combined ASTER MODIS Emissivity over Land (CAMEL) part 2: Uncertainty and validation. Remote Sens., 10, 664, https://doi.org/10.3390/rs10050664.

Fiebrich, C. A., J. E. Martinez, J. A. Brotzge, and J. B. Basara, 2003: The Oklahoma Mesonet's skin temperature network. J. Atmos. Oceanic Technol., 20, 1496-1504, https://doi.org/ 10.1175/1520-0426(2003)020<1496:TOMSTN>2.0.CO;2.

Fuchs, M., 1990: Infrared measurement of canopy temperature and detection of plant water stress. Theor. Appl. Climatol., 42, 253-261, https://doi.org/10.1007/BF00865986.

Gelaro, R., and Coauthors, 2017: The Modern-Era Retrospective Analysis for Research and Applications, version 2 (MERRA-2). J. Climate, 30, 5419-5454, https://doi.org/10.1175/JCLI-D-160758.1.

Göttsche, F.-M., and G. C. Hulley, 2012: Validation of six satelliteretrieved land surface emissivity products over two land cover types in a hyper-arid region. Remote Sens. Environ., 124, 149158, https://doi.org/10.1016/j.rse.2012.05.010.

_ , F.-S. Olesen, and A. Bork-Unkelbach, 2013: Validation of land surface temperature derived from MSG/SEVIRI with in situ measurements at Gobabeb, Namibia. Int. J. Remote Sens., 34, 3069-3083, https://doi.org/10.1080/01431161.2012.716539.

,,-- I. F. Trigo, A. Bork-Unkelbach, and M. A. Martin, 2016: Long term validation of land surface temperature retrieved from MSG/SEVIRI with continuous in-situ measurements in Africa. Remote Sens., 8, 410, https://doi.org/10.3390/ rs8050410.

Guillevic, P. C., J. L. Privette, B. Coudert, M. A. Palecki, J. Demarty, C. Ottlé, and J. A. Augustine, 2012: Land surface temperature product validation using NOAA's surface climate observation networks-Scaling methodology for the Visible Infrared Imager Radiometer Suite (VIIRS). Remote Sens. Environ., 124, 282-298, https:// doi.org/10.1016/j.rse.2012.05.004.

— ture products derived from the Visible Infrared Imaging Radiometer Suite (VIIRS) using ground-based and heritage satellite measurements. Remote Sens. Environ., 154, 19-37, https://doi.org/10.1016/j.rse.2014.08.013.

— validation best practice protocol, version 1.0. Land Product Validation Subgroup Publ., 60 pp.

Gunshor, M. M., T. J. Schmit, W. P. Menzel, and D. C. Tobin, 2009: Intercalibration of broadband geostationary imagers using AIRS. J. Atmos. Oceanic Technol., 26, 746-758, https:// doi.org/10.1175/2008JTECHA1155.1.

Heidinger, A. K., I. Laszlo, C. C. Molling, and D. Tarpley, 2013: Using SURFRAD to verify the NOAA single-channel 
land surface temperature algorithm. J. Atmos. Oceanic Technol., 30, 2868-2884, https://doi.org/10.1175/JTECHD-13-00051.1.

Hook, S. J., and Coauthors, 2004: In-flight validation and recovery of water surface temperature with Landsat-5 thermal infrared data using an automated high-altitude lake validation site at Lake Tahoe. IEEE Trans. Geosci. Remote Sens., 42, 27672776, https://doi.org/10.1109/TGRS.2004.839092.

— , R. G. Vaughan, H.Tonooka, and S. G. Schladow, 2007: Absolute radiometric in-flight validation of mid infrared and thermal infrared data from ASTER and MODIS on the Terra spacecraft using the Lake Tahoe, CA/NV, USA, automated validation site. IEEE Trans. Geosci. Remote Sens., 45, 17981807, https://doi.org/10.1109/TGRS.2007.894564.

_ , K. Cawse-Nicholson, J. Barsi, R. Radocinski, G. C. Hulley, W. R. Johnson, G. Rivera, and B. Markham, 2020: In-flight validation of the ECOSTRESS, Landsats 7 and 8 thermal infrared spectral channels using the Lake Tahoe CA/NV and Salton Sea CA automated validation sites. IEEE Trans. Geosci. Remote Sens., 58, 1294-1302, https://doi.org/10.1109/ TGRS.2019.2945701.

Hulley, G. C., and S. Hook, 2011: Generating consistent land surface temperature and emissivity products between ASTER and MODIS data for Earth science research. IEEE Trans. Geosci. Remote Sens., 49, 1304-1315, https://doi.org/10.1109/ TGRS.2010.2063034.

—-, S. Veraverbeke, and S. Hook, 2014: Thermal-based techniques for land cover change detection using a new dynamic MODIS multispectral emissivity product (MOD21). Remote Sens. Environ., 140, 755-765, https://doi.org/10.1016/ j.rse.2013.10.014.

_ _, N. K. Malakar, T. Islam, and R. J. Freepartner, 2018: NASA's MODIS and VIIRS land surface temperature and emissivity products: A long-term and consistent Earth system data record. IEEE J. Sel. Top. Appl. Earth Obs. Remote Sens., 11, 522-535, https://doi.org/10.1109/JSTARS.2017.2779330.

Idso, S. B., R. D. Jackson, and R. J. Reginato, 1976: Compensating for environmental variability in the thermal inertia approach to remote sensing of soil moisture. J. Appl. Meteor., 15, 811-817, https://doi.org/10.1175/1520-0450(1976)015<0811: CFEVIT $>2.0 . \mathrm{CO} ; 2$.

Ignatov, A., and G. Gutman, 1999: Monthly mean diurnal cycles in surface temperature over and land for global climate studies. J. Climate, 12, 1900-1910, https://doi.org/10.1175/15200442(1999)012<1900:MMDCIS>2.0.CO;2.

Inamdar, A. K., A. French, S. Hook, G. Vaughan, and W. Luckett, 2008: Land surface temperature retrieval at high spatial and temporal resolutions over the southwestern United States. J. Geophys. Res., 113, D07107, https://doi.org/10.1029/ 2007JD009048.

Karl, T. R., and Coauthors, 1993: A new perspective on recent global warming: Asymmetric trends of daily maximum and minimum temperature. Bull. Amer. Meteor. Soc., 74, 1007-1023, https://doi.org/10.1175/1520-0477(1993)074<1007: ANPORG $>2.0 . \mathrm{CO} ; 2$.

Karnieli, A., N. Agam, R. T. Pinker, M. Anderson, M. L. Imhoff, G. G. Gutman, N. Panov, and A. Goldberg, 2010: Use of NDVI and land surface temperature for drought assessment: Merits and limitations. J. Climate, 23, 618-633, https://doi.org/ 10.1175/2009JCLI2900.1.

Kustas, W., and M. Anderson, 2009: Advances in thermal infrared remote sensing for land surface modeling. Agric. For. Meteor., 149, 2071-2081, https://doi.org/10.1016/j.agrformet.2009.05.016.
Li, Z.-L., R. Tang, Z. Wan, Y. Bi, C. Zhou, B. Tang, G. Yan, and X. Zhang, 2009: A review of current methodologies for regional evapotranspiration estimation from remotely sensed data. Sensors, 9, 3801-3853, https://doi.org/10.3390/s90503801.

Malakar, N. K., G. C. Hulley, S. J. Hook, K. Laraby, M. Cook, and J. R. Schott, 2018: An operational land surface temperature product for Landsat thermal data: Methodology and validation. IEEE Trans. Geosci. Remote Sens., 56, 5717-5735, https://doi.org/ 10.1109/TGRS.2018.2824828.

Martin, M., and Coauthors, 2019: Comprehensive in situ validation of five satellite land surface temperature data sets over multiple stations and years. Remote Sens., 11, 479, https://doi.org/ $10.3390 / \mathrm{rs} 11050479$.

Matricardi, M., and R. Saunders, 1999: Fast radiative transfer model for simulation of Infrared Atmospheric Sounding Interferometer radiances. Appl. Opt., 38, 5679-5691, https:// doi.org/10.1364/AO.38.005679.

McFarland, M. J., R. L. Miller, and C. M. U. Neale, 1990: Land surface temperature derived from the SSM/I passive microwave brightness temperatures. IEEE Trans. Geosci. Remote Sens., 28, 839-845, https://doi.org/10.1109/36.58971.

McPherson, R. A., and Coauthors, 2007: Statewide monitoring of the mesoscale environment: A technical update on the Oklahoma Mesonet. J. Atmos. Oceanic Technol., 24, 301-321, https://doi.org/10.1175/JTECH1976.1.

Minnis, P., A. V. Gambheer, and D. R. Doelling, 2004: Azimuthal anisotropy of longwave and infrared window radiances from CERES TRMM and Terra data. J. Geophys. Res., 109, D08202, https://doi.org/10.1029/2003JD004471.

Ohmura, A., and Coauthors, 1998: Baseline Surface Radiation Network (BSRN/WCRP): New precision radiometry for climate research. Bull. Amer. Meteor. Soc., 79, 2115-2136, https://doi.org/ 10.1175/1520-0477(1998)079<2115:BSRNBW>2.0.CO;2.

Okuyama, A., and Coauthors, 2015: Preliminary validation of Himawari-8/AHI navigation and calibration. Proc. SPIE, 9607, 96072E, https://doi.org/10.1117/12.2188978.

Pinheiro, A. C. T., J. L. Privette, and P. Guillevic, 2006: Modeling the observed angular anisotropy of land surface temperature in a Savanna. IEEE Trans. Geosci. Remote Sens., 44, 10361047, https://doi.org/10.1109/TGRS.2005.863827.

Pinker, R. T., D. Sun, M.-P. Hung, C. Li, and J. B. Basara, 2009: Evaluation of satellite estimates of land surface temperature from GOES over the United States. J. Appl. Meteor. Climatol., 48, 167-180, https://doi.org/10.1175/2008JAMC1781.1.

Pinker, R. T, and Coauthors, 2019: Towards a unified and coherent land surface temperature Earth system data record from geostationary satellites. Remote Sens., 11, 1399, https://doi.org/ 10.3390/rs11121399.

Price, J. C., 1977: Thermal inertia mapping: A new view of the Earth. J. Geophys. Res., 82, 2582-2590, https://doi.org/10.1029/ JC082i018p02582.

Ren, H., X. Ye, R. Liu, J. Dong, and Q. Qin, 2018: Improving land surface temperature and emissivity retrieval from the Chinese Gaofen-5 satellite using a hybrid algorithm. IEEE Trans. Geosci. Remote Sens., 56, 1080-1090, https://doi.org/10.1109/ TGRS.2017.2758804.

Rossow, W. B., and R. A. Schiffer, 1991: ISCCP cloud data products. Bull. Amer. Meteor. Soc., 72, 2-20, https://doi.org/ 10.1175/1520-0477(1991)072<0002:ICDP>2.0.CO;2.

Saunders, R. W., M. Matricardi, and P. Brunel, 1999: An improved fast radiative transfer model for assimilation of satellite radiance observations. Quart. J. Roy. Meteor. Soc., 125, 1407-1425, https://doi.org/10.1002/qj.1999.49712555615. 
Scarino, B., P. Minnis, R. Palikonda, R. H. Reichle, D. Morstad, C. Yost, B. Shan, and Q. Liu, 2013: Retrieving clear-sky surface skin temperature for numerical weather prediction applications from geostationary satellite data. Remote Sens., $\mathbf{5}$, 342-366, https://doi.org/10.3390/rs5010342.

,-- T. Chee, K. M. Bedka, C. R. Yost, and R. Palikonda, 2017: Global clear-sky surface skin temperature from multiple satellites using a single-channel algorithm with angular anisotropy corrections. Atmos. Meas. Tech., 10, 351-371, https:// doi.org/10.5194/amt-10-351-2017.

Schmit, T. J., P. Griffith, M. M. Gunshor, J. M. Daniels, S. J. Goodman, and W. J. Lebair, 2017: A closer look at the ABI on the GOES-R series. Bull. Amer. Meteor. Soc., 98, 681-698, https://doi.org/10.1175/BAMS-D-15-00230.1.

Schmugge, T., S. J. Hook, and C. Coll, 1998: Recovering surface temperature and emissivity from thermal infrared multispectral data. Remote Sens. Environ., 65, 121-131, https://doi.org/ 10.1016/S0034-4257(98)00023-6.

Seemann, S. W., E. E. Borbas, R. O. Knuteson, G. R. Stephenson, and H.-L. Huang, 2008: Development of a global infrared land surface emissivity database for application to clear sky sounding retrievals from multispectral satellite radiance measurements. J. Appl. Meteor. Climatol., 47, 108-123, https:// doi.org/10.1175/2007JAMC1590.1.

Snyder, W., Z. Wan, Y. Zhang, and Y. Feng, 1998: Classification based emissivity for land surface temperature measurement from space. Int. J. Remote Sens., 19, 2753-2774, https://doi.org/ 10.1080/014311698214497.

Sobrino, J. A., and D. Skoković, 2016: Permanent stations for calibration/validation of thermal sensors over Spain. Data, 1, 10, https://doi.org/10.3390/data1020010.

— Z. Z. L. Li, M. P. Stoll, and F. Becker, 1994: Improvements in the split window technique for land surface temperature determination. IEEE Trans. Geosci. Remote Sens., 32, 243-253, https://doi.org/10.1109/36.295038.

Stone, D. A., and A. J. Weaver, 2002: Daily maximum and minimum temperature trends in a climate model. Geophys. Res. Lett., 29, 1356, https://doi.org/10.1029/2001GL014556.

— , and 2003: Factors contributing to diurnal temperature range trends in twentieth and twenty-first century simulations of the CCCma coupled model. Climate Dyn., 20, 435-445, https://doi.org/10.1007/s00382-002-0288-y.

Sun, D., and R. T. Pinker, 2003: Estimation of land surface temperature from a Geostationary Operational Environmental Satellite (GOES-8). J. Geophys. Res., 108, 4326, https://doi.org/ 10.1029/2002JD002422.

— and - 2005: Implementation of GOES-based land surface temperature diurnal cycle to AVHRR. Int. J. Remote Sens., 26 , 3975-3984, https://doi.org/10.1080/01431160500117634.

,-- , and M. Kafatos, 2006: Diurnal temperature range over the United States: A satellite view. Geophys. Res. Lett., 33, L05705, https://doi.org/10.1029/2005GL024780.

Susskind, J., and J. Blaisdell, 2008: Improved surface parameter retrievals using AIRS/AMSU data. Proc. SPIE, 6966, 696610, https://doi.org/10.1117/12.774759.
Taranik, J. V., and M. Settle, 1981: Space Shuttle: A new era in terrestrial remote sensing. Science, 214, 619-626, https:// doi.org/10.1126/science.214.4521.619.

Tomlinson, C. J., L. Chapman, J. E. Thornes, and C. Baker, 2011: Remote sensing land surface temperature for meteorology and climatology: A review. Meteor. Appl., 18, 296-306, https:// doi.org/10.1002/met.287.

Vinnikov, K. Y., Y. Yu, M. D. Goldberg, D. Tarpley, P. Romanov, I. Laszlo, and M. Chen, 2012: Angular anisotropy of satellite observations of land surface temperature. Geophys. Res. Lett., 39, L23802, https://doi.org/10.1029/2012GL054059.

Wan, Z., 2014: New refinements and validation of the collection-6 MODIS land-surface temperature/emissivity product. Remote Sens. Environ., 140,36-45, https://doi.org/10.1016/j.rse.2013.08.027.

— retrieving land-surface temperature from space. IEEE Trans. Geosci. Remote Sens., 34, 892-905, https://doi.org/10.1109/ 36.508406 .

_ , and Z.-L. Li, 1997: A physics-based algorithm for retrieving land-surface emissivity and temperature from EOS/MODIS data. IEEE Trans. Geosci. Remote Sens., 35, 980-996, https:// doi.org/10.1109/36.602541.

Wang, A., M. Barlage, X. Zeng, and C. S. Draper, 2014: Comparison of land skin temperature from a land model, remote sensing, and in situ measurement. J. Geophys. Res. Atmos., 119, 30933106, https://doi.org/10.1002/2013JD021026.

Wang, X., and C. Prigent, 2020: Comparisons of diurnal variations of land surface temperatures from numerical weather prediction analyses, infrared satellite estimates and in situ measurements. Remote Sens., 12, 583, https://doi.org/10.3390/rs12030583.

Weinreb, M. P., M. Jamieson, N. Fulton, Y. Chen, J. X. Johnson, J. Bremer, C. Smith, and J. Baucom, 2007: Operational calibration of Geostationary Operational Environmental Satellite8 and -9 imagers and sounders. Appl. Opt., 36, 6895-6904, https://doi.org/10.1364/AO.36.006895.

Young, A. H., K. R. Knapp, A. Inamdar, W. Hankins, and W. B. Rossow, 2018: The International Satellite Cloud Climatology Project H-series climate data record product. Earth Syst. Sci. Data, 10, 583-593, https://doi.org/10.5194/essd-10-583-2018.

Yu, Y., J. L. Privette, and A. C. Pinheiro, 2005: Analysis of the NPOESS VIIRS land surface temperature algorithm using MODIS data. IEEE Trans. Geosci. Remote Sens., 43, 23402350, https://doi.org/10.1109/TGRS.2005.856114.

—, D. Tarpley, J. L. Privette, M. D. Goldberg, M. K. Rama Varma Raja, K. L. Vinnikov, and H. Xu, 2009: Developing algorithm for operational GOES-R land surface, temperature product. IEEE Trans. Geosci. Remote Sens., 47, 936-951, https://doi.org/10.1109/TGRS.2008.2006180.

Zhang, B. L., R. T. Pinker, and P. W. Stackhouse, 2007: An empirical orthogonal function iteration approach for obtaining homogeneous radiative fluxes from satellite observations. J. Appl. Meteor. Climatol., 46, 435-444, https://doi.org/10.1175/JAM2478.1.

Zheng, X., Z.-L. Li, F. Nerry, and X. Zhang, 2019: A new thermal infrared channel configuration for accurate land surface temperature retrieval from satellite data. Remote Sens. Environ., 231, 111216, https://doi.org/10.1016/j.rse.2019.111216. 